University of Zurich

Department of Economics

Working Paper Series

ISSN 1664-7041 (print)

ISSN 1664-705X (online)

Working Paper No. 271

\title{
Gender Preference Gaps and Voting for Redistribution
}

Eva Ranehill and Roberto A. Weber

Revised version, December 2021 


\title{
Gender Preference Gaps and Voting for Redistribution
}

\author{
Eva Ranehill ${ }^{* a}$ and Roberto A. Weber ${ }^{b}$ \\ ${ }^{\text {a }}$ Department of Economics, University of Gothenburg \\ ${ }^{b}$ Department of Economics, University of Zurich
}

December 6, 2021

There is substantial evidence that women tend to support different policies and political candidates than men. Many studies also document gender differences in a variety of important preference dimensions, such as risk-taking, competition and pro-sociality. However, the degree to which differential voting by men and women is related to these gaps in more basic preferences requires an improved understanding. We conduct an experiment in which individuals in small laboratory "societies" repeatedly vote for redistribution policies and engage in production. We find that women vote for more egalitarian redistribution and that this difference persists with experience and in environments with varying degrees of risk. This gender voting gap is accounted for partly by both gender gaps in preferences and by expectations regarding economic circumstances. However, including both these controls in a regression analysis indicates that the latter is the primary driving force. We also observe policy differences between male- and female-controlled groups, though these are substantially smaller than the mean individual differences - a natural consequence of the aggregation of individual preferences into collective outcomes.

Keywords: gender differences; risk; altruism; redistributive preferences; experiment JEL codes: C91, C92, J16, H23

\footnotetext{
Corresponding author: Department of Economics, University of Gothenburg, Vasagatan 1 (eva.ranehill@economics.gu.se). We thank the Editor, Lise Vesterlund, and three anonymous referees for helpful comments and suggestions. We are also greatly thankful to Susanne Felder who provided valuable research assistance and inputs into earlier versions of this paper, as well as to participants at several conferences and seminars for helpful comments and suggestions. We thank the Swiss National Science Foundation (100010_149451) and the Jan Wallander and Tom Hedelius Foundation (Handelsbankens Forskningsstiftelser Grant P2010-0133:1) for generous financial support. The replication material for the study is available at https://doi.org/10.17605/OSF.IO/YNZ8X.
} 


\section{Introduction}

It is often claimed that the world, if run by women, would be very different than it is today (Funk and Gathmann 2015). ${ }^{1}$ However, since men have traditionally dominated cultural, political and economic decision making in most societies, we know very little about which institutions, policies and social outcomes would result if women were in charge. Nevertheless, as women become more involved and influential in corporate and policy decision making, it is important to better understand whether they do, in fact, implement distinct policies than those implemented by men.

The notion that having women in control of policymaking would produce a fundamentally different world is often supported by the observation, in the academic literature, of gender gaps in important areas of economic decision making and psychological traits (Bertrand 2011; Croson and Gneezy 2009; Niederle 2016). This literature finds women to be, on average, less risk taking, less confident and less willing to compete than men (e.g., Niederle and Vesterlund 2007; Eckel and Grossman 2008a; Niederle and Vesterlund 2010; Falk and Hermle 2018). In the context of pro-sociality, women are often relatively more concerned with equality than efficiency relative to men (e.g., Almås et al. 2010; Andreoni and Vesterlund 2001; Sutter et al. 2018). It seems plausible that preferences for less risk, competition and inequality would lead female-dominated societies to also be more equitable, more secure and less competitive. Indeed, other studies have documented that women tend to favor for more progressive redistributive policies (Alesina and Giuliano, 2011; Funk and Gathmann, 2015), which may be a manifestation of such gender gaps in more basic preferences.

However, while the observation of gender gaps in basic preferences presents a plausible channel through which greater involvement in policymaking by women may yield different policies and outcomes, more evidence about the precise relationships between such basic preferences and policy related behaviors, such as voting, are needed. For example, it is necessary to document that differences in the voting behavior of men and women are truly the result of stable preference differences for things like equality and security, rather than of economic circumstances that may lead women to benefit from more redistribution and a larger social safety net. In the latter case, gender gaps in policy preferences may diminish as women gain improved economic and political standing. Moreover, even if there is a channel from basic

\footnotetext{
${ }^{1}$ As an example, Christine Lagarde famously stated in 2010 that "If Lehman Brothers had been 'Lehman Sisters,' today's economic crisis clearly would look quite different." In a video interview published in 2019 by The Economist, former Liberian president Ellen Johnson Sirleaf stated, "If women were presidents all over the world, the world would be a safer place, it would be a more peaceful place, it would be a place of equality" (https://www.youtube.com/watch?v=PS9hlNhyRZY).
} 
preferences to voting, it is also necessary that such influence be sufficiently strong and robust to be consistently manifested in substantially different policy outcomes as the share of women holding decision-making authority increases.

Indeed, while several studies find that having women in power produces different policies and outcomes (e.g., Chattopadhyay and Duflo 2004; Matsa and Miller 2013), other studies fail to find such differences (e.g., Adams 2016; Eckbo, Nygaard and Thorburn 2016; Campa and Bagues 2021). The absence of stronger relationships may be because women do not inherently favor different kinds of policies or outcomes based on deep-seated underlying preference differences, or because decision-making institutions mitigate any differences in the manifestation of such preferences even as the share of female decision-makers increases.

In this paper, we use the control provided by laboratory experiments to investigate gender gaps in policy preferences and to understand better what factors are related to such gaps. ${ }^{2}$ In order to study voting behavior by gender in a manner that captures the basic features of many real-world policy decisions, we design a context in which groups of participants engage in real-effort production and endogenously determined redistribution. In each period of the main part of our experiment, group members first vote for their preferred redistributive policy - analogous to a linear tax rate - before engaging in production. Thus, participants state their preferred redistribution rule before they know their realized task income. In this setting, by means of their vote, participants can support egalitarian redistributive policies that decrease competition and risk and create greater equality or regressive policies that do the opposite. Our design thus yields a straightforward directional hypothesis for how previously documented gender gaps in preferences for risk, competition and equality should translate into policy preferences: women will vote for more egalitarian redistributive policies than men.

To better understand the basis for potential gender voting gaps, we also investigate the extent to which such gaps interact with the riskiness of the production environment. Our design varies by treatment whether individuals' output translates into wealth deterministically, meaning there is no risk, or is subject to random shocks that add risk to the relationship between productivity and income. This allows us to investigate whether women-who prior evidence

\footnotetext{
${ }^{2}$ While the ultimate objective should be to explore these relationships in broader populations and with regard to real-world policy outcomes, laboratory experiments are a valuable starting point. A laboratory environment allows us to precisely measure individual ability, relative performance beliefs, as well as a variety of economic preferences, and document whether they differ by gender. The laboratory also allows us to create a situation in which basic preferences can plausibly directly translate into voting behavior, in contrast with non-laboratory settings involving complex policies that bundle many dimensions related to gender preference gaps in various and sometimes conflicting ways.
} 
suggests tend to be more risk averse - exhibit a greater preference for more egalitarian policies, relative to men, as the riskiness of the production environment increases.

Consistent with the hypothesis that gender preference gaps translate into policy preferences we observe large gaps in voting behavior, with women preferring substantially more egalitarian redistributive policies than men. This gap persists over time, as participants gain experience and feedback in the production and redistribution environment. Moreover, while we find that participants vote for more egalitarian redistribution policies when the environment is inherently riskier, the gender gap in voting remains very similar both under low and high risk. Thus, differential risk preferences between men and women do not seem to result in varying gender gaps in demand for redistribution under varying degrees of risk, suggesting that gender gaps in risk preferences may not be a fundamental driver of the gender voting gap.

We then investigate more directly the degree to which gender gaps in voting are related to various individual preferences for which earlier research has documented gender gaps. We employ incentivized and unincentivized measures of risk preferences, social preferences and competitiveness. In each case, we confirm the typical behavioral gender gaps in the literaturewomen are more risk averse, less willing to compete and prioritize equality relative to efficiency to a greater degree than men. We then use these measures to test the extent to which these individual preference gaps account for the gender gap in voting for redistributive policies. We find that introducing these preferences into our regressions reduces part of the voting gaproughly 35 percent of the total gender gap in the first period and 22 percent of the gap in subsequent periods.

We also measure individual performance on the production task at the beginning of the experiment, before beginning the group activity involving voting and redistribution, and beliefs about relative performance. Consistent with earlier evidence that women are less overconfident than men, we find that women have less positive expectations regarding their relative performance on this initial task, even though actual performance does not differ by gender. Importantly, measures of relative performance beliefs account for between 40 and 50 percent of the gender gap in voting, suggesting that a large part of the gender gap is due to differential expectations of performance - and, therefore, income - in the production task. Moreover, when including controls for both preferences and performance beliefs in our regression analysis, gender preference gaps have only a limited impact on the gender voting gap, suggesting that differential expectations regarding economic circumstances are the primary driving force behind the gender voting gap. 
Finally, we study the extent to which the resulting group policies-which are determined in each period by the median vote in a group — vary depending on whether men or women are in majority. ${ }^{3}$ While it is natural to assume that a difference in the average preferences for a particular policy between men and women will lead policy outcomes in female- versus male-majority groups to reflect such differences, it is straightforward to show that collective decision making and intra-gender heterogeneity may often dampen these effects. ${ }^{4}$ Our results confirm this mechanical attenuation of the gender difference in policy preferences. The impact on policy outcomes of a group having a male or female majority is substantially smaller-by about half-relative to the difference between the individual preferences of men and women. Moreover, over the course of the 10 periods of our experiment, the gap in policies implemented in male- versus female-majority groups is not reliably statistically significant. While our experiment is only illustrative in this regard-since there could be many alternative social choice mechanisms for setting redistributive policy-it provides a demonstration that the gaps produced in female- versus male-majority decisionmaking bodies are likely to be smaller than the underling gender preference gaps.

Our results demonstrate that while part of the persistent and substantial gender gap in voting for redistribution can be connected to underling gender preference gaps - primarily for less competition and more equality - the gender gap in relative performance beliefs is the most important underlying factor. Our work thus indicates that gender gaps in preferences may have some influence on behavior and policy outcomes as women's participation in policymaking grows. However, our findings also suggest that this impact is secondary to that of beliefs about relative economic outcomes, which may change as women attain greater economic equality.

Moreover, the gaps in policy outcomes between male-majority and female-majority groups are substantially smaller than the gaps in male versus female policy preferences. Thus, we also provide interpretations for why many studies fail to find different outcomes as the

\footnotetext{
${ }^{3}$ While there are many possible social choice rules that one could explore with our design, implementing the median voter's preferences has several desirable properties (cf. Agranov and Palfrey 2015). It is a simple and easy to understand voting mechanism, and one that can be implemented quickly in repeated periods. The median voter's ideal point on a one-dimensional policy issue - the linear "tax rate" in our experiment —is also the outcome likely to arise under majority rule, per the median voter theorem.

${ }^{4}$ This results mechanically from the fact that the joint median when sampling from two distributions will typically lie between the medians (or means) of those distributions. However, to our knowledge, this argument has not been previously applied to argue why the impact of varying gender composition on policy may be small. We illustrate this point in Figure OA1 in the Online Appendix, which presents a simulation exploring how varying differences in the mean preferences of men and women translate into differential outcomes when either men or women are in the majority. The gaps in policies at the group level are considerably smaller-roughly $40-50 \%$-relative to mean gaps in individual-level preferences.
} 
gender composition of decision-making bodies changes: women may be less fundamentally motivated to pursue different policies than one might think by looking at their voting behavior, and the attenuating properties of collective decision-making rules may further dampen the effects of varying gender composition.

The remainder of this article is structured as follows. Section 2 discusses related literature. Section 3 describes the experiment design. Section 4 presents the results, first focusing on gender gaps in voting, then on the extent to which more basic gender preference gaps can explain the voting gap and, finally, on whether group outcomes differ between malemajority and female-majority groups. ${ }^{5}$ Section 5 concludes.

\section{Related Literature}

Our study relates to several different strands of research. One of these strands explores the extent to which women vote for different policies than men. While some studies indicate that women favor different policies than men, there is no consensus whether differences arise because women are intrinsically different than men, or whether they face different economic circumstances. For example, Funk and Gathmann (2015) and Alesina and Giuliano (2011) find that women in Switzerland and the US tend to have more favorable attitudes toward redistribution and to prioritize policies such as welfare more than men. This result holds even after controlling for a range of socio-economic characteristics, suggesting something intrinsically female about such policy preferences. However, Edlund and Pande (2002) find that the emergence of a gender gap in political preferences in the US from 1983 to 2003-with women voting more for left-leaning policies — strongly correlates with the decline in marriage. This leads the authors to speculate that the gender gap in political preferences results from higher divorce rates making men wealthier and women poorer.

Another related body of literature explores to what extent female leaders make different decisions than men, also finding somewhat contradictory results. For example, Chattopadhyay and Duflo (2004) study random political reservations for women in India and find that the public goods provided in villages with a female council head are more sensitive to the priorities

\footnotetext{
5 An earlier version of this paper, titled "Do Gender Preference Gaps Impact Policy Outcomes," was structured around testing four conditions: (1) whether gender gaps in basic preferences are robust, (2) whether they translate into voting behavior, (3) whether such voting behavior translates into different policy outcomes in male- and female-majority groups and (4) whether these differences persist with repetition and feedback. Based on helpful suggestions from anonymous reviewers and the editor, we reorganized the current paper to start by documenting voting gaps (2) and their persistence with experience (4), then investigating the extent to which such gaps can be accounted for by gaps in more basic preferences (1) and finally exploring the extent to which such gaps robustly influence policy outcomes at the group level (3). The substantive results are unchanged.
} 
of female constituencies. However, Campa and Bagues (2021) find no impact of gender quotas in candidate lists in local Spanish elections on the size or composition of public spending. Exploring the impact of female representation in the private sector, Matsa and Miller (2013) find that companies affected by a Norwegian quota requiring a minimum of $40 \%$ female board members experience higher labor costs - due to fewer layoffs compared to companies unaffected by the quota - and lower operating profits. However, Eckbo et al. (2016) question Matsa and Miller's findings (2013) by arguing that extending the sample period generates a non-significant effect of the quota on company value. ${ }^{6}$ When taken together, evidence of an impact of increased representation of female decision-makers is thus mixed. Moreover, some of this research suggests that, rather than fundamentally different societies-less competitive, less risky, more egalitarian - female policy control may mainly produce societies that prioritize policies more directly beneficial to women. ${ }^{7}$

Implicitly, this literature connects the impact of a larger share of female decisionmakers on outcomes with gender preference gaps, although there is no clear measurement of these policymakers' or managers' preferences or beliefs, nor of the extent to which these traits are responsible for differences in enacted policies. It is, however, an important connection to test, given that it is relevant for understanding the nature and stability of gender gaps in preferences for specific policies and outcomes.

A large body of research documents gender gaps in economic preferences related to risk, competitiveness and pro-sociality, as well as relative performance beliefs (for reviews, see Croson and Gneezy 2009; Bertrand 2011; Niederle 2016). While many studies find support for systematic gender gaps (e.g., Pulford and Colman 1997; Niederle and Vesterlund, 2007; Eckel and Grossman, 2008a; Falk et al. 2015), some recent literature raises questions about their generality and magnitude. For instance, recent reviews argue that the gender gap in risk attitudes may be smaller and less reliable than previously thought (Filippin and Crosetto 2016; Niederle 2016; Nelson 2015). Similarly, while many studies find a large gender gap in the willingness to enter competitive environments, most of these studies rely on a common, mathbased, paradigm inspired by Niederle and Vesterlund's (2007) seminal article. Other studies indicate that gender differences in competitiveness sometimes disappear-for example, in tasks that are not male stereotyped (Cárdenas et al. 2012; Dreber, Essen, and Ranehill 2014;

\footnotetext{
${ }^{6}$ Some experimental studies exploring whether male versus female managers adopt different incentives find contradictory results. Price (2011) finds male and female managers to be equally likely to implement tournament compensation as opposed to piece-rate incentives, but Shurchkov and van Geen (2019) find that men implement competitive incentives more often.

${ }^{7}$ For a recent overview of this literature, see Hessami and da Fonseca (2020).
} 
Günther et al. 2010; Grosse, Riener, and Dertwinkel-Kalt 2014; Shurchkov 2012, although see also, e.g., Wozniak, Harbaugh, and Mayr 2014), when time pressure is reduced (Shurchkov 2012), or when information about relative performance is available (Ertac and Szentes 2011; Wozniak et al 2014; though Cason, Masters, and Sheremeta 2010 find the opposite result). Turning to pro-sociality, meta-analyses of dictator-game giving by Engel (2011) and Bilén, Dreber and Johannesson (2020) find only small gender differences. However, several studies suggest that men and women differ in their preferences for efficiency versus equality, rather than in general pro-sociality (Almås et al. 2010; Andreoni and Vesterlund 2001; Sutter et al. 2018). Finally, a large literature indicates that women are often less confident in their ability than are men, but this finding is sometimes moderated by the stereotype associated with the relevant task (e.g., Lundeberg, Fox, and Punćcohaŕ 1994; Barber and Odean 2001; Niederle and Vesterlund 2007). ${ }^{8}$

Perhaps most closely related to our work are a few studies that explore the relationships between basic preferences for risk and equality and political preferences, finding some evidence that such basic preferences may partly explain gender gaps in policy preferences. Gärtner, Mollerstrom and Seim (2017) survey a representative sample of 1,365 Swedish adults to study the relationship between risk preferences and general support for redistribution. They measure risk preferences using eight hypothetical choices between a safe amount and a lottery and measure attitudes toward redistribution by asking, "How much economic redistribution do you want in society?" Controlling for other observable characteristics, women exhibit slightly more support for redistribution, but this relationship is not robustly statistically significant. Introducing the risk aversion measure-which significantly predicts attitudes toward redistribution - decreases the magnitude of the gender coefficients by about 15 percent. $^{9}$

Fisman, Jakiela and Kariv (2017) use a web survey to elicit the distributional preferences of a large sample of Americans. They then explore the extent to which the resulting

\footnotetext{
${ }^{8}$ Exploring the extent to which typical gender gaps may persist past the glass ceiling, Adams and Funk (2011) survey directors and CEOs of publicly listed Swedish companies. While they find many similarities between male and female CEOs, they also find that female directors are less risk averse than their male counterparts, suggesting a reversal of the basic gender gap in preferences they find among a representative sample. Thus, while there is often apparent agreement that gender differences in some behavioral characteristics are robust and large, such gaps may be limited to a more specific set of contexts and conditions than sometimes suggested in the literature. ${ }_{9}^{9}$ More precisely, in a model without controls for socio-economic status - but controlling for age, marital status, number of children, education and employment status - women exhibit more favorable attitudes toward redistribution, by 0.100 of a standard deviation (with a standard error of 0.059 ) and this coefficient is marginally statistically significant $(p<0.1$ ). Adding controls for socio-economic status decreases the coefficient to 0.084 (with a standard error of 0.058) and the relationship is no longer statistically significant. These coefficients suggest a modest tendency for women to express more positive attitudes toward redistribution. Adding risk aversion as an explanatory variable decreases the gender coefficients to $0.085(0.059)$ and $0.070(0.059)$, respectively.
} 
preference types exhibit differential support for Barack Obama and the Democratic Party in the 2012 Presidential Election. While their study is not explicitly about gender, women in their sample are more likely to prioritize equality over efficiency, though the statistical significance of this relationship is not robust to corrections for multiple hypothesis testing. Women are also more likely to report having voted for Obama and for the Democratic party - though neither relationship is statistically significant. Controlling for distributional preferences decreases the relationships between gender and voting for Obama and Democrats by 14 percent and 19 percent, respectively. ${ }^{10}$

Hence, these studies find some evidence of gender differences in preferences for risk and for equality versus efficiency and, in exploratory analysis, identify that these preference gaps may have an impact on support for statements favoring redistribution or for a specific leftleaning political candidate. But they do not clearly demonstrate that women vote for different policies than men, nor are they designed to investigate, more broadly, the degree to which gender gaps in preferences and expectations influence policy preferences.

Finally, only a few studies in economics investigate the extent to which gender differences in policy preferences at the individual level persist through collective decisionmaking. ${ }^{11}$ Dufwenberg and Muren (2006) explore the relationship between group gender composition and sharing decisions in the dictator game, finding that female-majority groups are more generous than male-majority groups. A few studies explore whether the existence and size of speculative bubbles in experimental asset markets depend on the gender composition of the traders. Eckel and Füllbrunn (2015) find an inverse relationship between the magnitude of price bubbles and the share of female traders. However, Cueva and Rustichini (2015) find all measures of mispricing to be comparable, or worse, in all-female markets than in all-male markets, while Eckel and Füllbrunn (2017) find no differences when subjects are not informed of the market gender composition. Moreover, Eckel and Füllbrunn (2015) find that gender gaps in individual-level preferences, such as risk aversion, have weak and statistically insignificant

\footnotetext{
${ }^{10}$ A recent study by Buser et al. (2020) conducts secondary analysis on data from two earlier experimental studies involving redistribution, conducted in eight university laboratories in four countries. They find that women demand more redistribution than men in only one of the eight locations (one of three in the US). Even then, this gender gap only arises in some choices (e.g., when income is based on performance rather than luck and when individuals have no information on their pre-tax income), but not in others (e.g., when individuals know their pretax income).

${ }^{11}$ A related strand of literature explores whether the gender composition of teams impacts performance (for a review, see Azmat and Petrongolo (2014)). For example, Apesteguia, Azmat and Irriberi (2012) use data on threeperson teams performing in a large online business game. They find that all-female teams perform the worst, and this is explained by, among other things, all female teams implementing a less aggressive pricing strategy, and investing more in sustainability initiatives than other types of teams.
} 
relationships with bubble formation. Hence, these studies provide only modest evidence of links between basic behavioral gender gaps and the outcomes produced by male- versus female-controlled groups.

\section{Experimental Design}

Our experiment consisted of three parts. ${ }^{12}$ In Part 1 we elicited individual preferences related to risk and concern for others. Participants also answered questions about their age and gender. In Part 2 we elicited participants' baseline productivity in the production task, as well as their preferences for competition and their relative performance beliefs. Participants received no information about outcomes or earnings for Parts 1 and 2 until the end of the study.

In the main part, Part 3, participants performed the production task with redistribution in fixed groups of five, for 10 periods. Groups varied with respect to their gender composition, although at no point were participants made aware of the identity or gender of their group members. ${ }^{13}$ Finally, after Part 3, we once again elicited individual productivity. Subjects also completed an exit questionnaire.

The experiment comprised two conditions, which varied only with respect to how participants earnings were generated. Specifically, the conditions varied whether participants were paid a fixed piece rate for their output (the No Risk condition), or whether individuals' income was subject to random shocks (the Risk condition). We first describe the experiment as implemented in the No Risk condition, and then explain how the Risk condition differs.

\subsection{Parts 1 and 2: Preferences, Productivity, and Performance Beliefs}

We began by eliciting a variety of individual preferences using both incentivized and non-incentivized measures. Participants did not receive feedback about the outcome in any of the measures elicited in Parts 1 and 2 until the end of the study. We elicited these preference measures before the main part of the study (Part 3), since this subsequent part provided full feedback about relative performance and economic outcomes, which would likely have contaminated the basic preference measures.

As an incentivized measure of risk preferences we implemented the investment game of Gneezy and Potters (1997) in which participants allocated a portion of an initial endowment of 100 Experimental Currency Units (ECU) to a risky investment. The investment failed with

\footnotetext{
${ }^{12}$ Complete instructions are provided in Appendix B.

13 As we describe in more detail below, we oversampled the assignment of men and women to single gender groups to increase variability of group composition. The number of such groups is too small to allow for a meaningful statistical analysis, and these groups are not analyzed separately.
} 
a probability of $50 \%$, in which case the invested money was lost, while with $50 \%$ probability the investment returned 2.5 times the invested amount. We also elicited risk preferences through a non-incentivized survey question about general risk-taking propensity introduced by Dohmen et al. (2011).

We also elicited social preferences using two incentivized measures and one nonincentivized survey question. For the incentivized measures we used the full version of the Social Value Orientation scale (Murphy, Ackermann and Handgraaf 2011), in which participants make 15 choices allocating wealth between one's self and another randomly selected participant. Choices in the first 6 decisions (the "Primary" dimension) allow a classification of a participant's type along a spectrum of pro-social motivations, from competitive to altruistic. The remaining 9 decisions ("Secondary") identify a subject's willingness to trade off equality versus efficiency. As a non-incentivized measure, we administered a hypothetical question about how much a participant would donate to charity if he or she unexpectedly received 1,000 Swiss Francs (Dohmen et al. 2011).

In Part 2, participants performed the real-effort production task that would form the basis of the main part of the experiment once under piece-rate incentives to provide us with a measure of individual productivity. The task was a computerized version of a digit-substitution task (Iriberri and Rey-Biel 2011; Erkal, Gangadharan and Nikiforakis 2011). ${ }^{14}$ Participants were shown keys, consisting of a unique mapping of 9 letters to numbers, and could decode sequences of three letters into numbers (see Figure 1). Keys were changed every ninth threeletter sequence. If a sequence was decoded incorrectly, a participant had to decode the same sequence until the entry was correct. Participants had 90 seconds to decode as many sequences as possible and received a payment of $10 \mathrm{ECU}$ for each correct entry.

After participants performed the task under piece-rate incentives, we elicited their willingness to engage in competition. To save time, the measure implemented differs from the measure introduced by Niederle and Vesterlund (2007) in that participants were asked to choose between piece-rate or tournament pay for their previous performance instead of performing the task again. Under the piece rate, a participant received a second payment identical to his or her earlier payment for performance (10 ECU per correctly completed entry).

\footnotetext{
${ }^{14}$ The task was originally developed as part of the Wechsler Adult Intelligence Scale (Wechsler, 1958) and involves both memory and codification abilities and requires a mixture of effort and ability. We implemented this particular production task because we judged the task to have a neutral gender stereotype and because previous research shows the task to yield both no significant gender differences in performance and considerable variation in performance (Iriberri and Rey-Biel 2011). While the first characteristic simplifies the analysis by not biasing the effect of the redistribution policy by gender, the second is necessary to create a motive for redistribution.
} 
Alternatively, under the competitive payment, the participant's score was compared to that of a randomly selected other participant and yielded either double the original piece-rate payment (20 ECU per correct entry) if the participant's performance was higher or, otherwise, yielded nothing. Ties were broken randomly. This binary choice is our measure of competitiveness.

\section{Figure 1: The digit-letter substitution task}

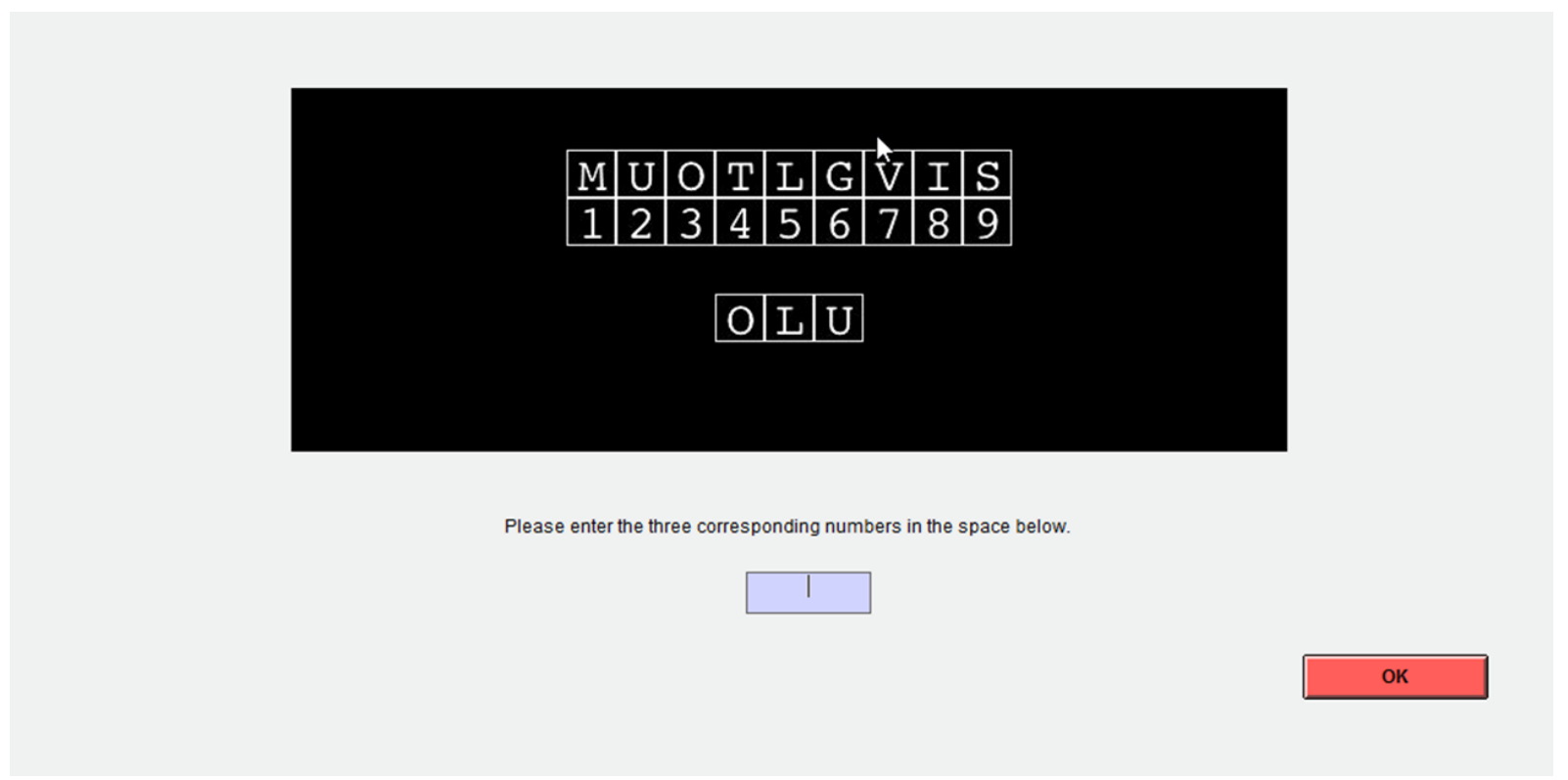

We also elicited subjects' beliefs about their relative task performance. At the conclusion of Part 2, participants guessed their performance rank in the task relative to other participants in the experimental session. Accurate responses were incentivized: participants received an extra payment of $50 \mathrm{ECU}$ if their guessed rank was within two of their actual rank. ${ }^{15}$

\subsection{Part 3: Repeated Production with Redistribution}

At the beginning of Part 3, participants were randomly assigned to five-person groups. These groups then remained the same for the 10 periods of Part 3.

In each period, groups performed the same activity involving voting, production and redistribution. Participants first voted for their preferred redistribution policy and then observed the policy implemented for their group in that period. Group members thereafter engaged in the real-effort production task and generated income according to the piece-rate scheme as in Part 2. Once the production phase was over, this income was subject to redistribution per the

\footnotetext{
${ }^{15}$ Incentivizing beliefs potentially creates a hedging motive. However, widespread hedging would suggest a negative relationship between actual rank and guessed rank, which we do not see in our data. Gächter and Renner (2010) find that incentives increase belief accuracy, leading us to opt in favor of incentivized beliefs.
} 
policy determined at the beginning of the period. At the end of the period, participants received detailed information about individual outcomes for all group members, as described below.

\subsubsection{The Vote}

At the beginning of each period, all five group members simultaneously cast a vote for a redistribution parameter, $t \in[-1.00,1.00]$, analogous to a linear tax rate. Following the vote, all group members observed the resulting redistribution parameter, determined by the median vote, which would be applied to the group earnings at the end of the relevant period. Using the median vote, in contrast to using, for example, the average vote, implies that each participant is incentivized to provide his or her preferred value of $t$, reducing strategic voting. This fact was also stressed in the instructions.

\subsubsection{Production}

After the vote, participants worked independently on the real-effort production task. As in Part 2, each production period lasted 90 seconds, and each correctly completed entry generated 10 ECU of income. In the Risk condition, this certain 10 ECU was replaced by a stochastic payment, as described below.

\subsubsection{Redistribution}

Following production in a period, task income was redistributed according to the implemented redistribution policy for that period. Given a policy, $t$, defined by the median vote, the formula for calculating final payoffs in a period is given by:

$$
\pi_{i}\left(x_{i}, x_{j \neq i}, t\right)=(1-t) x_{i}+t \sum_{i=1}^{n} \frac{1}{n} x_{i}
$$

In this equation, $\pi_{i}$ denotes the final payoff of individual $i, x_{i}$ denotes the individual's pre-tax earnings from production and $x_{j \neq i}$ other individual group members' earnings.

The instructions carefully described the properties of the tax rate to the participants. It was clearly explained that redistribution is made by collecting a portion of the individual earnings from production and redistributing this amount back to group members. Subjects were informed that positive values of $t$ attenuate income inequalities, while negative values of $t$ amplify them. ${ }^{16}$

\footnotetext{
${ }^{16}$ The instructions also provided detailed examples in text and in tables of the impact of negative and positive redistribution coefficients, and illustrated the three special cases of $t=-1,0$ and 1 . Finally, all participants also answered control questions consisting of numerical examples of both negative and positive redistribution policies.
} 
Some special cases illustrate the redistributive policies allowed by this mechanism. Egalitarian and maximin policies coincide at $t=1$, when all participants receive the same payoff. Libertarian and meritocratic choices coincide at $t=0$, in which case everyone retains their income from production. Purely selfish behavior implies a vote for $t=-1$ by participants who perform above the group mean, and a vote for $t=1$ by participants who perform below the mean. ${ }^{17}$

\subsubsection{Learning Measurement and Exit Questionnaire}

After the 10th and last period, participants ended the study with one final round of the production task. This round of the real-effort task was incentivized through the same piece rate as before, $10 \mathrm{ECU}$ per completed entry; but, in this case, there was no redistribution. We included this additional performance measure to get an indication of the level of learning in the task, since a participant's task performance across the 10 periods of the production and redistribution activity may be influenced both by learning, or by strategic responses to implemented redistribution policies.

We also administered an exit questionnaire. This comprised various questions about demographics and political orientation.

\subsubsection{Conditions: No Risk vs. Risk}

To explore the effects of introducing risk into the production context, the Risk condition added random variation in the individual performance payments in the 10 periods of Part 3. This was implemented by letting the computer randomly draw a productivity parameter in each period, separately for each participant. This parameter was equally likely to be any integer from 0 to 20 . The number of ECU generated from the production task in a period by a group member in the Risk condition equaled the number of correct entries times this random productivity parameter. Part 3 was otherwise identical between conditions.

\subsection{Implementation and Information}

The experiment took place in English at the University of Zurich. We recruited 415 students from the University of Zurich and the Swiss Federal Institute of Technology using the software h-root (Bock, Baetge and Nicklisch 2014). We conducted 17 sessions-16 sessions with 25 participants and one with 15-using the software z-Tree (Fischbacher 2007). In total,

\footnotetext{
${ }^{17}$ When $t$ was negative, we limited its magnitude such that no group member would have negative earnings in a period. Specifically, the program adjusted $t$ upwards such that the least productive group member received a payoff of 0 . This adjustment occurred rarely (in 4.6 percent of cases).
} 
200 participants took part in the No Risk condition and 215 in the Risk condition. In each session, five randomly chosen men and five randomly chosen women were assigned to samesex groups for Part 3, while the remaining participants were randomly grouped, independently of their sex. In total we have 18 all-female, 17 all-male, and 48 mixed groups. Table 1 presents the number of male- and female-majority groups by treatment. ${ }^{18}$

Table 1: Overview of Experiment

\begin{tabular}{l|cc|cc} 
& \multicolumn{2}{|c|}{ Subjects } & \multicolumn{2}{c}{ Groups } \\
& Male & Female & Male majority & Female majority \\
\hline No Risk & 107 & 93 & 25 & 15 \\
Risk & 111 & 104 & 25 & 18 \\
\hline Total & 218 & 197 & 50 & 33 \\
\hline
\end{tabular}

Participants received full instructions, which were also read aloud, for each part of the study at the onset of that part. They were informed that each part was independent, such that any decision taken in one part would not influence the course of events in other parts. We took several steps to clearly explain the instructions and procedures, particularly emphasizing the redistribution mechanism. Immediately after receiving detailed instructions about the mechanism, participants spent three minutes interacting with a calculation screen in which they could test the effect of different redistribution parameters for any hypothetical distribution of earnings among the five group members. This screen was also available when answering control questions. Participants also saw the same calculation screen for 60 seconds at the onset of each subsequent period, together with information from all prior periods about the five group members' earnings from production and final earnings.

Each period concluded with feedback. In addition to the redistributive policy, participants saw a table indicating, for each group member in that period, the income generated from production, the member's rank in the group, the net transfers and final earnings. A scrollable box also provided information on the redistribution policy, as well as each group member's production and final earnings, for all previous periods.

In addition to a $10 \mathrm{CHF}$ participation payment, participants were paid for all incentivized tasks, and for all 10 periods of the production and redistribution activity in Part 3.

\footnotetext{
${ }^{18}$ One all-male group and two all-female groups arose through random group assignment. There was a slight gender imbalance in our remaining population, as men attended the experiment more frequently. This yielded a substantially higher proportion of male-majority groups through random group assignment.
} 
Earnings in ECU were converted to money at the rate of 50 ECU to 1 Swiss Franc (CHF). Participants earned, on average, 50.5 CHF (approximately 54 USD).

\section{Results}

We first test whether we replicate the gender gaps in basic preferences widely observed in the literature. Next, we study whether we observe gender voting gaps in Part 3 that are consistent with women supporting more progressive redistributive policies. We then test whether our individual-level measures of preferences and expectations reproduce gender gaps widely documented in the literature and, if so, to what extent these gaps provide a basis for gender gaps in voting behavior. Finally, we examine to what extent gender gaps in policy preferences impact the policies implemented in groups with different gender majorities.

\subsection{Gender Gaps in Policy Preferences}

Recall that votes for the redistribution parameter, $t$, may range from -1 to 1 , with higher values corresponding to more egalitarian policies. Figure 2 shows the average vote for the redistribution parameter, separately for men and women, across the 10 periods of Part 3. Panel A shows data from the No Risk condition, while Panel B shows the Risk condition.

Figure 2: Mean vote across periods by gender and treatment
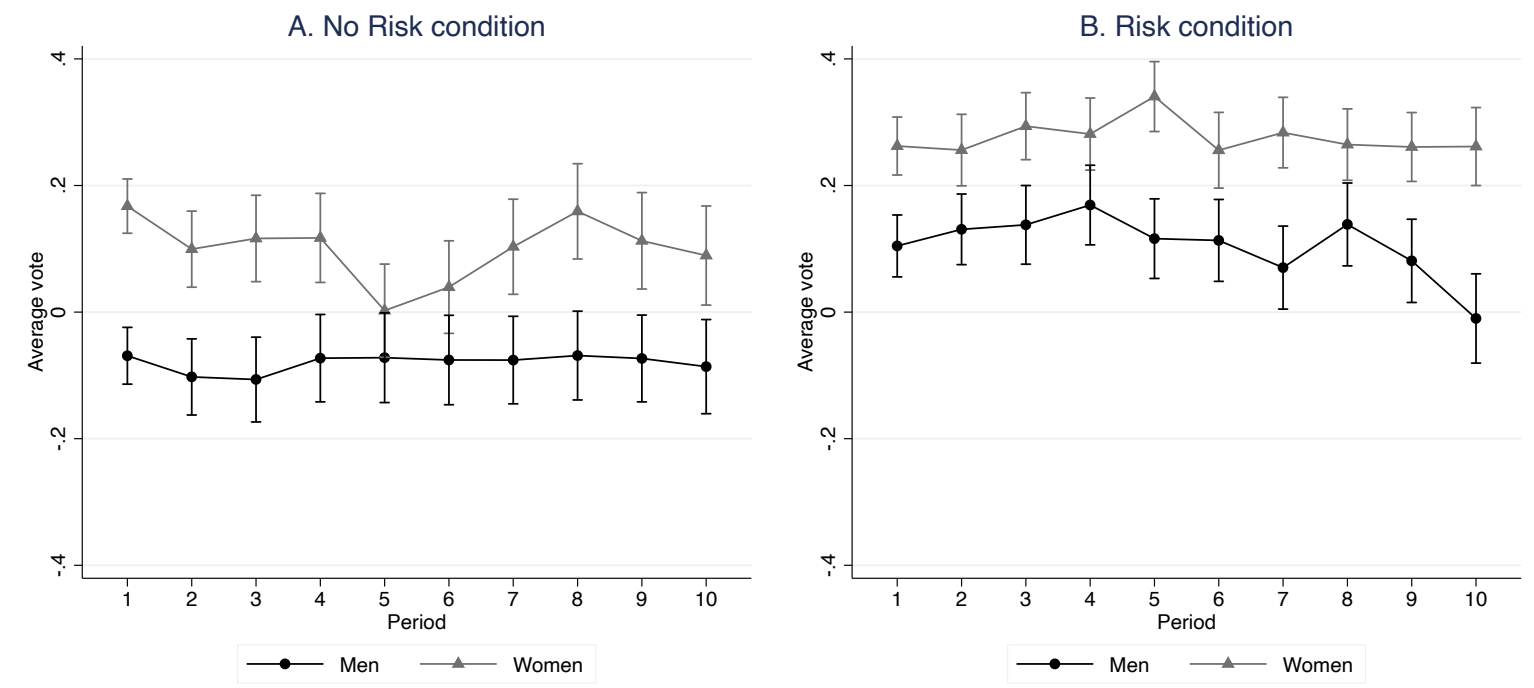

Standard errors in parentheses

A comparison of male and female votes in the first period supports the hypothesis that women favor more egalitarian redistribution. In Period 1 of the No Risk condition, men on average vote for negative redistribution coefficients $\left(\bar{t}_{N R}^{M}=-0.069\right)$, while women on average 
vote for egalitarian redistribution $\left(\bar{t}_{N R}^{F}=0.167\right)$ and the difference in means is statistically significant $\left(t_{198}=3.78, p<0.001\right)$. In the Risk condition, both men and women vote for more egalitarian redistribution relative to the No Risk condition, but men again vote for less egalitarian policies on average $\left(\bar{t}_{R}^{M}=0.105, \bar{t}_{R}^{F}=0.262, t_{213}=2.348, p=0.020\right) .{ }^{19}$

These gender gaps in voting generally extend to subsequent periods. In both the No Risk and Risk conditions women vote, on average, for higher redistribution coefficients than men in all periods. While there is some variation over time in the average votes, there do not seem to be substantial and persistent time trends.

Table 2: The gender gap in voting

\begin{tabular}{lcc|ccc}
\hline Dependent variable: & \multicolumn{2}{c}{ Vote (Period 1) } & \multicolumn{3}{c}{ Vote (All Periods) } \\
& $(1)$ & $(2)$ & $(3)$ & $(4)$ & $(5)$ \\
\hline Female & $0.198^{* * *}$ & $0.236^{* * *}$ & $0.179^{* * *}$ & $0.181^{* * *}$ & $0.164^{* * *}$ \\
& $(0.049)$ & $(0.058)$ & $(0.046)$ & $(0.058)$ & $(0.046)$ \\
Risk condition & & $0.173^{* * *}$ & & $0.185^{* * *}$ & \\
Female & & $(0.064)$ & & $(0.066)$ & \\
X Risk condition & & -0.079 & & -0.010 & \\
Period & & $(0.094)$ & & $(0.087)$ & \\
& & & & & -0.004 \\
Female X Period & & & & & $0.004)$ \\
& & & & & 0.003 \\
Constant & 0.019 & $-0.069^{*}$ & 0.014 & $-0.080^{* *}$ & 0.039 \\
& $(0.035)$ & $(0.036)$ & $(0.036)$ & $(0.039)$ & $(0.038)$ \\
\hline Observations (subjects) & 415 & 415 & 4,150 & 4,150 & 4,150 \\
R-squared & 0.042 & 0.064 & 0.028 & 0.056 & 0.028 \\
\hline
\end{tabular}

Estimates from linear regressions. Models 1 and 2 use only data from the first period; Models 3 through 5 use votes in all 10 periods and include random effects at the subject level. Standard errors (clustered at the group level) in parentheses; *** $\mathrm{p}<0.01,{ }^{* *} \mathrm{p}<0.05,{ }^{*} \mathrm{p}<0.1$.

Table 2 analyzes voting patterns by gender using linear regressions. Models 1 and 2 study first-period votes, while Models 3 through 5 study voting across all 10 periods and include random effects at the subject level. All models cluster standard errors at the group level. The main observation from this table is that, across all specifications, the gender gap is sizable.

\footnotetext{
${ }^{19}$ Online Appendix Figure OA2 shows the cumulative distributions of first-period votes by gender and condition; within each condition, the distribution of female votes first-order stochastically dominates that of male votes. For both conditions, the distributions of first-period votes also differ significantly in non-parametric Wilcoxon ranksum tests (No Risk: $z=3.738, p<0.001$; Risk: $z=2.209, p=0.027$ ). Women also tend to vote substantially more frequently for policies that produce greater equality (i.e., $t>0$ ) than do men (No Risk: 33/107 (31\%) for men versus 55/93 (59\%) for women; Risk: 57/111 (51\%) for men versus 74/104 (71 percent) for women).
} 
Women vote for redistribution policies between 0.164 to 0.236 higher than those of men, and this gender gap is statistically significant ( $p<0.002$ in all models).

Models 2 and 5 additionally include an indicator variable for the Risk condition and for its interaction with gender. The introduction of risk produces votes for more egalitarian redistribution policies - an impact roughly comparable to that of the gender gap. However, there is no significant interaction between the risk condition and gender, indicating that women are no more likely to favor more egalitarian redistribution in the presence of greater income risk. This provides an initial indication that the gender gap in voting may not be substantially influenced by differences in risk preferences between men and women. Finally Model 5 confirms that there seems to be no substantial change across periods in the types of policies supported by men versus women, consistent with the lack of clear trends in Figure 2.

\subsection{What Drives Gender Gaps in Policy Preferences?}

Having established that women tend to vote for redistribution policies that implement less risk and competition and more equality, we next investigate the extent to which this gap can be accounted for by gaps in more basic preferences. Since Table 2 reveals no interaction between gender and our experimental conditions in voting behavior, in most of our subsequent analysis we control for the Risk condition but omit interaction terms.

\subsubsection{Gender preference gaps}

Table 3 lists the individual-level measures elicited in Parts 1 and 2, with averages presented separately by gender. We replicate many of the gender gaps observed in earlier research. Men exhibit greater risk tolerance both in the incentivized investment task and in the survey question. The incentivized primary measure of Social Value Orientation, capturing the degree to which an individual puts positive weight on another's payoff, shows women are only slightly more pro-socially oriented than men. On the secondary Social Value Orientation measure, however, which identifies a preference for efficiency over equality, we find that women are relatively more equality than efficiency oriented than men. ${ }^{20}$ Women further state a higher willingness to donate money in a non-incentivized survey question. Finally, men are

\footnotetext{
${ }^{20}$ The Social Value Orientation's first six items yield a score between -45 and 90 degrees, representing the direction (degree) of an individual's preferences on a two-dimensional space corresponding to own payoff (horizontal axis) and another's payoff (vertical axis), yielding a spectrum from purely altruistic (90), to pro-social (45), individualistic (0) and competitive (-45). The remaining 9 items measure a tendency to prioritize equality (0) versus efficiency (1). The table reports the scores on the secondary measure for the entire sample of 415 participants. Restricting our analysis to the 160 individuals who expressed a pro-social orientation yields a similar gender gap (men: 0.64 (0.03), women: 0.54 (0.02); $d=0.408 ; \mathrm{p}<0.001)$.
} 
also more willing to have their payment determined through a competitive incentive scheme.

The final three rows show performance in the task under piece rate incentives - in Part 2 and at the end of the experiment - along with beliefs about relative performance elicited in Part 2. We construct relative performance beliefs by converting the incentivized guess of relative rank in the session into a score from 0 (worst) to 100 (best). Men tend to believe that their Part 2 task performance ranks higher than do women, and this difference is statistically significant. This is consistent with earlier work documenting a gender gap in confidence. ${ }^{21}$ The second to last row in Table 3 presents the average actual performance on the real-effort production task in Part 2. We observe a slight, but statistically insignificant difference between male and female performance at this stage. The distributions of initial performance also do not differ significantly ( $\mathrm{p}=0.481$, using a Kolmogorov-Smirnov test). However, importantly for our purposes, we find ample variation in initial task performance: the minimum performance is 5, the maximum performance is 23 and only 14 percent of observations lie at the median of 12. This is important, as such variation creates a potential motive for redistribution.

Table 3: Gender gaps in preferences, expectations and task performance

\begin{tabular}{|c|c|c|c|c|}
\hline Variable & Men & Women & Cohen's $d$ & p-value \\
\hline $\begin{array}{l}\text { Risk (Investment task) } \\
\text { (incentivized 0-100, } 100=\text { risky) }\end{array}$ & $\begin{array}{l}70.54 \\
(2.02)\end{array}$ & $\begin{array}{l}55.72 \\
(1.88)\end{array}$ & 0.525 & $<0.001$ \\
\hline $\begin{array}{l}\text { Risk (Survey question) } \\
\text { (non-incentivized } 0-10,10=\text { risk taking) }\end{array}$ & $\begin{array}{c}6.10 \\
(0.15)\end{array}$ & $\begin{array}{c}5.03 \\
(0.16)\end{array}$ & 0.481 & $<0.001$ \\
\hline $\begin{array}{l}\text { Social Value Orientation (Primary) } \\
\text { (Incentivized, }-45=\text { competitive; } 90=\text { altruistic) }\end{array}$ & $\begin{array}{l}17.12 \\
(0.94)\end{array}$ & $\begin{array}{r}18.26 \\
(0.95)\end{array}$ & -0.084 & 0.298 \\
\hline $\begin{array}{l}\text { Social Value Orientation (Secondary) } \\
\text { (Incentivized, } 0=\text { egalitarian; } 1=\text { efficiency) }\end{array}$ & $\begin{array}{c}0.67 \\
(0.01)\end{array}$ & $\begin{array}{c}0.61 \\
(0.01)\end{array}$ & 0.408 & $<0.001$ \\
\hline $\begin{array}{l}\text { Giving (Survey question) } \\
\text { (non-incentivized, } 0-1000,1000=\text { generous) }\end{array}$ & $\begin{array}{l}135.55 \\
(11.93)\end{array}$ & $\begin{array}{l}202.34 \\
(12.24)\end{array}$ & -0.384 & $<0.001$ \\
\hline $\begin{array}{l}\text { Competitiveness } \\
(0 \text { or } 1,1=\text { competitive })\end{array}$ & $\begin{array}{c}0.43 \\
(0.03)\end{array}$ & $\begin{array}{c}0.16 \\
(0.03)\end{array}$ & 0.614 & $<0.001$ \\
\hline $\begin{array}{l}\text { Relative performance beliefs (Part 2) } \\
\text { (guessed rank: } 0=\text { worst; } 100=\text { best) }\end{array}$ & $\begin{array}{l}54.56 \\
(1.17)\end{array}$ & $\begin{array}{l}45.57 \\
(1.16)\end{array}$ & 0.534 & $<0.001$ \\
\hline $\begin{array}{l}\text { Average performance } \\
\text { (Initial piece rate in Part 2) }\end{array}$ & $\begin{array}{l}12.05 \\
(0.19)\end{array}$ & $\begin{array}{l}11.61 \\
(0.17)\end{array}$ & 0.164 & 0.188 \\
\hline $\begin{array}{l}\text { Average performance } \\
\text { (Final piece rate) }\end{array}$ & $\begin{array}{l}17.14 \\
(0.24)\end{array}$ & $\begin{array}{r}16.34 \\
(0.20)\end{array}$ & 0.247 & $0.018^{\mathrm{a}}$ \\
\hline Observations & 218 & 197 & & \\
\hline
\end{tabular}

\footnotetext{
${ }^{21}$ We can directly measure overconfidence by comparing the rank provided by a subject to the actual performance rank. Men, on average, state a rank that is better than their actual rank (by 1.15), while women are slightly underconfident $(-0.09)$. This difference is marginally statistically significant $(p=0.076$, Wilcoxon rank-sum).
} 
Standard error of the mean in parentheses. The table reports p-values from Wilcoxon Mann-Whitney tests. Cohen's $d$ is a standardized measure of the difference in means between two variables (the difference in means divided by the pooled standard deviation).

a Since the data in the final piece-rate round are not independent, we also estimated a linear regression of performance on gender, clustering standard errors by group. This also yields a significant difference $(p=0.010)$.

Table 3 additionally presents average performance in the final instance of the task, performed at the end of the experiment under piece-rate incentives. We find evidence of learning by both men and women-performance is considerably higher in this final measure than in the initial one, by 42 and 41 percent for men and women, respectively. We also find that the initially small male advantage is now larger and statistically significant in a Wilcoxon rank-sum test, although, the distributions of performance by gender at the end of the study do not differ significantly ( $\mathrm{p}=0.121$, Kolmogorov-Smirnov test) ${ }^{22}$

\subsubsection{Determinants of voting in Period 1}

We next investigate our main question: to what extent do gender gaps in the individual characteristics in Table 3 account for the gender voting gap? We first focus on Period 1, where participants have no experience with the production and redistribution activity in their group.

Table 4 presents regressions with a participant's first period vote as the dependent variable. In Model 1, we identify the overall gender effect on votes, with only the risk condition as a control; this replicates the pattern of findings from Table 2, where we observed both a gender gap and treatment effect on voting, which were largely independent of each other.

Models 2 through 5 introduce the individual preference measures for risk, pro-sociality and competitiveness from Table 3, first separately for each domain and then jointly. ${ }^{23}$ For comparability, we standardize all preference measures, except for the binary measure of competitiveness. Model 2 introduces the two measures of risk-seeking, finding that neither has a statistically significant relationship with voting in the first period. Their introduction lowers the coefficient for gender slightly, by about 10 percent. Model 3 introduces the measures of

\footnotetext{
${ }^{22}$ Figure OA3 in the Online Appendix provides data on performance across periods, separately for men and women. There is an apparent, though small, discontinuity in performance between Period 10 (with redistribution) and the final piece-rate performance measure (without redistribution). This suggests some strategic reduction of effort in response to the presence of redistribution.

23 Table OA1 in the Online Appendix presents regressions that introduce each measure separately. The two measures of risk preferences have the expected negative coefficients (i.e., risk seeking is negatively correlated with the preferred redistribution policy) but are statistically insignificant. The Primary SVO and the survey question on giving, which can be interpreted as measuring concern for others' welfare, have positive coefficients, though only the Primary SVO is statistically significant $(p<0.01)$. The Secondary SVO, which measures emphasis on efficiency over equality, has a negative and statistically significant coefficient $(p<0.01)$. Finally, the two measures of performance and beliefs have negative and statistically significant $(p<0.02)$ coefficients when introduced separately. Online Appendix Table OA2 presents the raw correlations between first-period votes and each of the preference and belief measures, separately by gender and treatment.
} 
pro-social concerns, finding that both Social Value Orientation measures predict voting in the expected directions - i.e., more altruistic concern and greater egalitarianism are associated with a preference for more positive redistribution coefficients - and both relationships are statistically significant. The unincentivized survey measure of pro-sociality has little 
Table 4: The impact of preferences and performance beliefs on first-period votes

\begin{tabular}{|c|c|c|c|c|c|c|c|}
\hline \multirow[t]{2}{*}{ Dependent variable: } & \multicolumn{7}{|c|}{ Vote (Period 1) } \\
\hline & (1) & (2) & (3) & (4) & (5) & (6) & (7) \\
\hline Female & $\begin{array}{l}0.196^{* * *} \\
(0.048)\end{array}$ & $\begin{array}{l}0.177^{* * *} \\
(0.049)\end{array}$ & $\begin{array}{l}0.165^{* * *} \\
(0.045)\end{array}$ & $\begin{array}{l}0.161^{* * *} \\
(0.050)\end{array}$ & $\begin{array}{l}0.127^{* * *} \\
(0.048)\end{array}$ & $\begin{array}{l}0.122^{* *} \\
(0.049)\end{array}$ & $\begin{array}{c}0.080 \\
(0.049)\end{array}$ \\
\hline Risk condition & $\begin{array}{l}0.136^{* * *} \\
(0.049)\end{array}$ & $\begin{array}{l}0.142^{* * *} \\
(0.050)\end{array}$ & $\begin{array}{l}0.125^{* *} \\
(0.049)\end{array}$ & $\begin{array}{l}0.135^{* * *} \\
(0.048)\end{array}$ & $\begin{array}{l}0.124^{* * *} \\
(0.050)\end{array}$ & $\begin{array}{l}0.105^{* *} \\
(0.047)\end{array}$ & $\begin{array}{l}0.097^{* *} \\
(0.048)\end{array}$ \\
\hline $\begin{array}{l}\text { Risk preferences } \\
\text { (Investment task, standardized) }\end{array}$ & & $\begin{array}{c}0.001 \\
(0.024)\end{array}$ & & & $\begin{array}{c}0.023 \\
(0.024)\end{array}$ & & $\begin{array}{c}0.019 \\
(0.024)\end{array}$ \\
\hline $\begin{array}{l}\text { Risk preferences } \\
\text { (Survey question, standardized) }\end{array}$ & & $\begin{array}{l}-0.040 \\
(0.027)\end{array}$ & & & $\begin{array}{l}-0.034 \\
(0.027)\end{array}$ & & $\begin{array}{l}-0.040 \\
(0.026)\end{array}$ \\
\hline $\begin{array}{l}\text { Social Value Orientation - Primary } \\
\text { (competitive-altruistic, standardized) }\end{array}$ & & & $\begin{array}{l}0.067^{* *} \\
(0.026)\end{array}$ & & $\begin{array}{l}0.069^{* *} \\
(0.026)\end{array}$ & & $\begin{array}{l}0.067^{* * *} \\
(0.025)\end{array}$ \\
\hline $\begin{array}{l}\text { Social Value Orientation - Secondary } \\
\text { (egalitarian-efficiency, standardized) }\end{array}$ & & & $\begin{array}{c}-0.056^{* * *} \\
(0.021)\end{array}$ & & $\begin{array}{l}-0.052^{* *} \\
(0.023)\end{array}$ & & $\begin{array}{l}-0.042^{*} \\
(0.022)\end{array}$ \\
\hline $\begin{array}{l}\text { Giving } \\
\text { (Survey question, standardized) }\end{array}$ & & & $\begin{array}{c}0.009 \\
(0.023)\end{array}$ & & $\begin{array}{c}0.012 \\
(0.024)\end{array}$ & & $\begin{array}{c}0.009 \\
(0.024)\end{array}$ \\
\hline $\begin{array}{l}\text { Competition } \\
(1=\text { competitive })\end{array}$ & & & & $\begin{array}{c}-0.129^{* *} \\
(0.050)\end{array}$ & $\begin{array}{l}-0.124^{* *} \\
(0.049)\end{array}$ & & $\begin{array}{l}-0.050 \\
(0.046)\end{array}$ \\
\hline $\begin{array}{l}\text { Relative Part } 2 \text { performance beliefs } \\
\text { (standardized) }\end{array}$ & & & & & & $\begin{array}{c}-0.139^{* * *} \\
(0.024)\end{array}$ & $\begin{array}{c}-0.125^{* * * *} \\
(0.023)\end{array}$ \\
\hline Part 2 task performance (standardized) & & & & & & $\begin{array}{l}-0.015 \\
(0.023)\end{array}$ & $\begin{array}{l}-0.021 \\
(0.023)\end{array}$ \\
\hline Constant & $\begin{array}{l}-0.050 \\
(0.036) \\
\end{array}$ & $\begin{array}{l}-0.044 \\
(0.034) \\
\end{array}$ & $\begin{array}{l}-0.029 \\
(0.034) \\
\end{array}$ & $\begin{array}{c}0.006 \\
(0.040)\end{array}$ & $\begin{array}{c}0.026 \\
(0.039)\end{array}$ & $\begin{array}{c}0.001 \\
(0.035)\end{array}$ & $\begin{array}{c}0.040 \\
(0.038) \\
\end{array}$ \\
\hline Observations & 415 & 415 & 415 & 415 & 415 & 415 & 415 \\
\hline R-squared & 0.062 & 0.069 & 0.104 & 0.076 & 0.122 & 0.145 & 0.189 \\
\hline
\end{tabular}

Estimates from linear regressions. Standard errors (clustered at the group level) in parentheses, ${ }^{* * *} \mathrm{p}<0.01,{ }^{* *} \mathrm{p}<0.05,{ }^{*} \mathrm{p}<0.1$. 
relationship with voting. Introducing these measures of pro-social concern lowers the coefficient for female by about 15 percent. Finally, Model 4 shows that a preference for competition is associated with voting for lower redistribution coefficients and that this relationship is statistically significant. Introducing this preference measure lowers the gender coefficient by roughly 18 percent. Model 5 introduces all of the preference measures jointly; this lowers the coefficient for female by 35 percent, though the relationship between gender and voting remains statistically significant. This indicates that the elicited preference measures can account for part of the gender voting gap, though a large part of the gap remains unexplained. $^{24}$

In Models 6 and 7, we introduce two measures of expected relative task performance. First, we introduce the incentivized measure of beliefs regarding relative task performance in Part 2, when participants completed the task under piece-rate incentives. This measure is negatively associated with the preferred redistribution coefficient, indicating that subjects who expect to perform (relatively) better on the decoding task vote for less egalitarian redistribution. We also include actual Part 2 task performance. This seems to have little predictive value in this model, though when included individually it also has a negative and statistically significant coefficient (see Online Appendix Table OA1). Introducing these measures of expected task performance lowers the coefficient for female by about 38 percent relative to Model 1, indicating that a substantial part of the gender gap in voting is driven by differential performance expectations.

Model 7 includes all preference and belief measures jointly. In this case, the coefficient for female is reduced by almost 60 percent and is no longer statistically significant $(p=0.11)$. Further, the primary Social Value Measure of altruistic concern is the only preference measure that remains significant, suggesting that relative performance beliefs may drive a large part of the impact on voting of the gender gap in competitiveness. Thus, combining our preference measures with measures of performance beliefs, the belief measures seem to account for a large part of the gender gap in voting, while preference measures have diminished explanatory power. Moreover, including all of these measures jointly substantially reduces the explanatory

\footnotetext{
${ }^{24}$ In additional exploratory analysis (not reported here), we find that maternal and paternal education, number of siblings and age do not correlate with votes. However, participants who report being toward the right, rather than left, of the political spectrum vote for lower redistribution coefficients (No Risk: -0.031 (Right) vs. 0.111 (Left), $p=0.027$; Risk: 0.081 (Right) vs. 0.260 (Left), $p=0.009$, using a median split of self-reported political orientation), providing suggestive evidence that voting in our experiment may be related to political preferences outside the laboratory.
} 
power of gender. ${ }^{25}$

\subsubsection{Determinants of voting in Periods 2 through 10}

We next investigate the degree to which basic preferences impact voting in the remaining periods of Part 3. This provides us with some insight into whether the influence of preference gaps persists through the process of repeated experience and learning. ${ }^{26}$

Table 5 reports regressions similar to those in Table 4, but using votes in Periods 2 through 10 as the dependent variable. Model 1 again reproduces the observation of a substantial gender gap in voting, along with a gap based on risk in the production task. Model 2 introduces the preference measures collected in Parts 1 and 2. This model is comparable to Model 5 in Table 4, but in contrast to the model for Period 1, where social preferences had significant explanatory power, only the coefficient for competitiveness remains statistically significant when predicting behavior in later periods. The introduction of the preference measures lowers the coefficient for gender by approximately 22 percent, which is smaller than the reduction of approximately 35 percent between Models 1 and 5 in Table 4 .

Model 3 adds two measures of relative performance beliefs. First, we introduce the same measure of subjects' beliefs from Part 2 that we used in Model 6 in Table 4. Second, we use the subjects' lagged relative performance rank in the group as a proxy for beliefs about future relative performance. Both measures are standardized, with higher scores indicating higher (expected) performance. Both coefficients indicate that better expected performance is statistically significantly associated with votes for lower redistribution coefficients $(p<$ 0.001). Introducing these measures reduces the size of the gender coefficient by roughly 50 percent and this coefficient is now marginally statistically significant ( $p=0.053)$. Thus, as in Period 1, relative performance expectations seem to play at least as large a role in determining the gender gap in voting as our preference measures for risk, pro-sociality and competitiveness.

Finally, Model 4 combines all of the explanatory variables. The coefficients for the two measures of expected relative performance retain their magnitudes and statistical significance,

\footnotetext{
${ }^{25}$ We also estimated separate versions of Model 7 for men and for women (see Online Appendix Table OA1), to study whether the relationship between our explanatory variables and the dependent variable differs by gender. These regressions indicate that performance beliefs significantly predict the chosen redistribution coefficient for both genders $(p<0.01)$. For women, but not for men, the primary Social Value Orientation is also a significant predictor $(p=0.001)$.

${ }^{26}$ While there is variation in individual voting behavior across periods, we also find substantial consistency over time. For example, there is a strong positive correlation (0.82) between average votes in Periods 1-5 and in Periods 6-10 (see Online Appendix Figure OA4). This consistency may be partly explained by the high positive correlation of 0.70 between the individual performance rankings from one period to the next throughout the experiment.
} 
but the coefficient for competitiveness is substantially smaller and no longer statistically significant, underlining the importance of performance beliefs for the gender gap in voting. In this model, the coefficient for gender is 60 percent smaller than in Model 1 and no longer statistically significant $(p=0.152) .{ }^{27}$

Table 5: The impact of preferences and performance beliefs on votes in Periods 2-10 Dependent variable: Vote (Periods 2-10)

\begin{tabular}{|c|c|c|c|c|}
\hline & $(1)$ & (2) & (3) & (4) \\
\hline Female & $\begin{array}{l}0.173^{* * *} \\
(0.047)\end{array}$ & $\begin{array}{l}0.135^{* *} \\
(0.053)\end{array}$ & $\begin{array}{l}0.085^{*} \\
(0.044)\end{array}$ & $\begin{array}{c}0.069 \\
(0.048)\end{array}$ \\
\hline Risk condition & $\begin{array}{c}0.186^{* * *} \\
(0.041)\end{array}$ & $\begin{array}{c}0.177^{* * *} \\
(0.062)\end{array}$ & $\begin{array}{c}0.160^{* * *} \\
(0.041)\end{array}$ & $\begin{array}{c}0.156^{* * *} \\
(0.042)\end{array}$ \\
\hline $\begin{array}{l}\text { Risk preferences } \\
\text { (Investment task, standardized) }\end{array}$ & & $\begin{array}{c}0.033 \\
(0.032)\end{array}$ & & $\begin{array}{c}0.020 \\
(0.028)\end{array}$ \\
\hline $\begin{array}{l}\text { Risk preferences } \\
\text { (Survey question, standardized) }\end{array}$ & & $\begin{array}{l}-0.017 \\
(0.029)\end{array}$ & & $\begin{array}{l}-0.018 \\
(0.024)\end{array}$ \\
\hline $\begin{array}{l}\text { Social Value Orientation - Primary } \\
\text { (competitive-altruistic, standardized) }\end{array}$ & & $\begin{array}{c}0.028 \\
(0.031)\end{array}$ & & $\begin{array}{c}0.032 \\
(0.027)\end{array}$ \\
\hline $\begin{array}{l}\text { Social Value Orientation - Secondary } \\
\text { (egalitarian-efficiency, standardized) }\end{array}$ & & $\begin{array}{l}-0.021 \\
(0.026)\end{array}$ & & $\begin{array}{l}-0.018 \\
(0.023)\end{array}$ \\
\hline $\begin{array}{l}\text { Giving } \\
\text { (Survey question, standardized) }\end{array}$ & & $\begin{array}{l}-0.009 \\
(0.027)\end{array}$ & & $\begin{array}{l}-0.011 \\
(0.023)\end{array}$ \\
\hline $\begin{array}{l}\text { Competition } \\
(1=\text { competitive })\end{array}$ & & $\begin{array}{c}-0.150^{* *} \\
(0.066)\end{array}$ & & $\begin{array}{l}-0.064 \\
(0.055)\end{array}$ \\
\hline $\begin{array}{l}\text { Relative Part } 2 \text { performance beliefs } \\
\text { (standardized) }\end{array}$ & & & $\begin{array}{c}-0.120^{* * *} \\
(0.024)\end{array}$ & $\begin{array}{c}-0.111^{* * *} \\
(0.024)\end{array}$ \\
\hline $\begin{array}{l}\text { Lagged relative performance } \\
\text { (standardized) }\end{array}$ & & & $\begin{array}{c}-0.172^{* * *} \\
(0.016)\end{array}$ & $\begin{array}{c}-0.172^{* * *} \\
(0.015)\end{array}$ \\
\hline Constant & $\begin{array}{c}-0.081^{* *} \\
(0.035)\end{array}$ & $\begin{array}{l}-0.013 \\
(0.043)\end{array}$ & $\begin{array}{l}-0.026 \\
(0.034)\end{array}$ & $\begin{array}{c}0.003 \\
(0.039)\end{array}$ \\
\hline Observations & 3,735 & 3,735 & 3,735 & 3,735 \\
\hline R-squared & 0.050 & 0.068 & 0.377 & 0.385 \\
\hline
\end{tabular}

Estimates from linear regressions with random effects at the subject level. Robust standard errors in parentheses, ${ }^{* * *} \mathrm{p}<0.01,{ }^{* *} \mathrm{p}<0.05,{ }^{*} \mathrm{p}<0.1$.

To conclude the analysis of individual voting, our results suggest some impact of gender gaps in preferences for pro-sociality and competitiveness in accounting for the gender voting

\footnotetext{
${ }^{27}$ We also estimated versions of Model 4, separately, for the No Risk and Risk conditions (see Online Appendix Table OA3). The only substantive difference is that the coefficient for lagged relative performance is roughly twice as large in magnitude in the No Risk condition $(-0.231(0.024))$ than in the Risk condition $(-0.120(0.018))$. Table OA3 also reports separate versions of Model 4 for each set of three periods (2-4, 5-7, 8-10). The results are generally similar to those in Table 4; perhaps the most notable difference is that the coefficient for competitiveness is marginally statistically significant in Periods 1-3 $(p=0.069)$.
} 
gap. However, a more important determinant of the gender voting gap appears to be differential performance expectations. In Period 1, perceptions of relative task ability account for 38 percent of the gender voting gap, while in Periods 2 through 10 they account for approximately one-half of this gap.

\subsection{Does Gender Composition Impact Group Policy Choices?}

We now investigate the degree to which gender gaps in voting translate into differential outcomes in male- versus female-majority groups. Recall that individual votes were aggregated into collective outcomes through a median-voting rule.

Figure 3 presents the average policy implemented across the 10 periods of Part 3 , separately for each condition and for male-majority and female-majority groups. The final set of markers for each condition shows the mean redistribution policy across all periods, using the average in a group across all periods as the unit of observation. Consistent with our observations of voting at the individual level, groups in the Risk condition implement more egalitarian redistribution policies than those in the No Risk condition.

\section{Figure 3. Average redistribution policy by group composition and treatment}

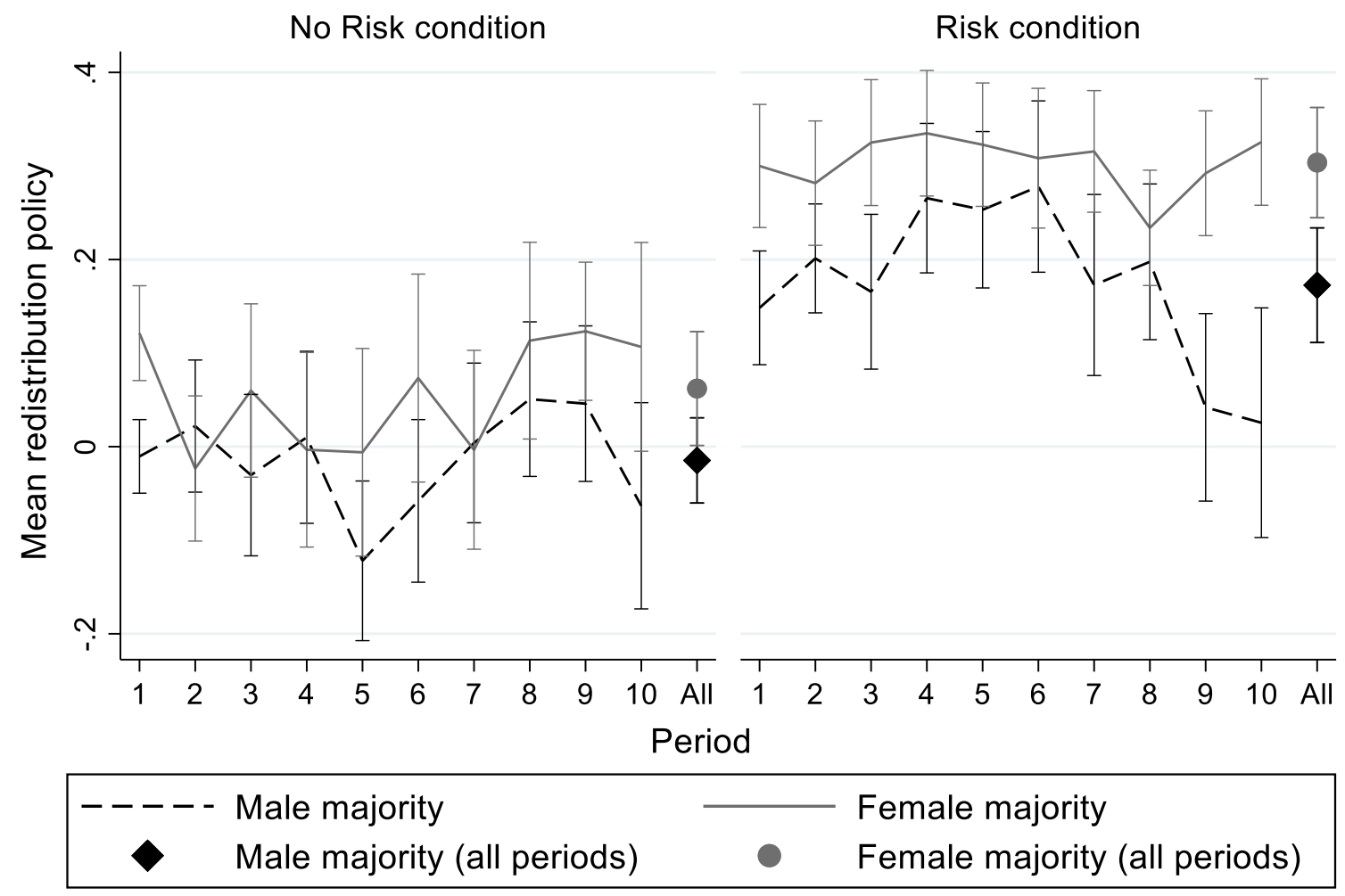

Bars represent standard errors 
In the first period, majority-female groups implement more egalitarian redistribution policies, relative to male-majority groups, both in the No Risk condition $\left(\bar{t}_{\text {male maj }}=\right.$ $\left.-0.010 ; \bar{t}_{\text {fem maj }}=0.121 ; t_{38}=2.053, p=0.047\right)$ and in the Risk condition $\left(\bar{t}_{\text {male maj }}=\right.$ $\left.0.148 ; \bar{t}_{\text {fem maj }}=0.300 ; t_{41}=1.669, p=0.103\right)$. Thus, groups in which women hold policy control tend to implement more progressive redistribution, but the gaps in outcomes are smaller than the mean voting gaps between men and women that we observed earlier. ${ }^{28}$ This naturally results from the central tendency of an aggregation mechanism such as median voting.

Over the remainder of the 10 periods, female-majority groups generally - though not always-implement more egalitarian redistributive policies than male-majority groups. Pooling across all periods, the average implemented redistribution policy is higher in femalemajority groups in both the No Risk $\left(\bar{t}_{\text {male maj }}=-0.015 ; \bar{t}_{\text {fem maj }}=0.062\right)$ and Risk $\left(\bar{t}_{\text {male maj }}=0.173 ; \bar{t}_{\text {fem maj }}=0.304\right)$ conditions. However, these differences in means are not statistically significant when using the average policy in a group across the 10 periods of Part 3 as an observation (No Risk: $t_{38}=1.020, p=0.314$; Risk: $t_{41}=1.492, p=0.144$ ). ${ }^{29}$

Table 6 presents regression analysis of the group policies implemented across the 10 periods of Part 2, using the redistribution policy in a group in a period as the dependent variable. The table follows a similar structure to our earlier analyses of individual voting (e.g., Table 4). Model 1 includes as explanatory variables whether the group had a male or female majority and the treatment condition. Groups with more women than men tend to implement more egalitarian redistribution policies, although the coefficient is only marginally statistically

\footnotetext{
${ }^{28}$ Recall that our design oversamples groups with extreme (all-male, all-female) gender compositions. This means that the policy gaps between male- and female-majority groups might be exaggerated relative to what would arise if group gender composition were determined by forming groups at random from the entire population. Our firstperiod data, in which group members have no prior feedback from any interactions with other participants, provide insight into what kind of gaps would arise between male-majority and female-majority groups if they had been formed at random. For each condition, we conducted 10,000 simulations in which we formed groups by randomly sampling individuals from the entire population within that condition, recording whether the group had a male or female majority, and implementing as "policy" the median Period 1 vote in the artificial group. In No Risk, the mean policy enacted in male-majority groups is 0.010 and for female-majority groups it is 0.096 ; the gap of 0.085 is smaller than the actual first-period gap in our experiment (0.132). In Risk, the mean policies are 0.176 (malemajority) and 0.244 (female-majority), and the gap of 0.067 is again smaller than the actual first-period gap we observed (0.152).

${ }^{29} \mathrm{We}$ also investigated differences between male-majority and female-majority groups in other outcome measures. For example, across the 10 periods of Part 3, male-majority groups generated more completed tasks per period than female-majority groups in the No Risk condition (male majority: 69.24; female majority: $63.72 ; t_{38}=$ 3.342; $p<0.01$ ), but not in the Risk condition (male majority: 63.62 ; female majority: $64.58 ; t_{41}=0.764 ; p=$ 0.450 ). At least part of the difference in the No Risk condition appears to be driven by initial differences in task ability. We observe no significant differences between male-majority and female-majority groups in the resulting degrees of inequality, measured by group-level Gini coefficients of final individual payoffs from Part 3.
} 
significant $(p=0.081)$ and the magnitude of the difference $(0.102)$ is roughly half as large as the gender gap in individual voting (cf. Model 1 in Tables 4 and 5).

The remaining models introduce measures of preferences in the group as explanatory variables, in a manner similar to that in our earlier analysis of individual voting behavior.

Since the critical voter in a group is the median voter, we use the median preference in a group as the explanatory variable to capture the potential influence of the most relevant preferences on group outcomes; this is analogous to our measure of the impact of gender, Female majority, which identifies whether the median gender is female. Looking at Models 2 through 5, the median risk preferences (Model 2) and competitiveness (Model 4) in a group do little to account for the policy gap between male- and female-majority groups. However, introducing measures of social preferences (Model 3) reduces the size of the gender majority coefficient by roughly 60 percent, with the median response to the hypothetical giving question providing the most explanatory power. Model 5, which introduces all of the preference measures jointly, shows that this social preference measure persists in having a statistically significant relationship with the group policy when simultaneously introducing the other measures of median group preferences. Models 6 and 7 additionally introduce the measures of expected task performance from Table 4- the median belief in the group about relative task performance in Part 2 and the median actual task performance in Part 2. The negative (though generally not statistically significant) coefficients indicate that groups in which the median expected or actual performance in Part 2 is higher also tend to adopt less egalitarian redistribution coefficients. Comparing Models 1 and 7, we see that accounting for the median preferences and performance expectations in a group accounts for a large proportion (approximately 70 percent) of the policy gap between male-majority and female-majority groups.

\section{Conclusion}

We study the relationship between gender gaps in policy preferences and gaps in more basic preferences. There is widespread evidence that men and women differ in their attitudes toward risk, competition and inequality. Several studies also document that men and women sometimes exhibit different voting behavior, with women favoring greater redistribution. However, the degree to which gender gaps in the policy preferences of men and women are the direct result of more basic preference gaps - rather than of other factors, such as differential 
Table 6: Implemented redistribution policies and group composition

Dependent variable:

Policy implemented in group (Periods 1-10)

\begin{tabular}{|c|c|c|c|c|c|c|c|}
\hline & (1) & (2) & (3) & (4) & (5) & (6) & (7) \\
\hline Risk condition & $\begin{array}{l}0.213^{* * *} \\
(0.058)\end{array}$ & $\begin{array}{l}0.209^{* * *} \\
(0.060)\end{array}$ & $\begin{array}{l}0.214^{* * *} \\
(0.056)\end{array}$ & $\begin{array}{l}0.207^{* * *} \\
(0.059)\end{array}$ & $\begin{array}{l}0.202^{* * *} \\
(0.057)\end{array}$ & $\begin{array}{l}0.175^{* * *} \\
(0.060)\end{array}$ & $\begin{array}{l}0.153^{* *} \\
(0.060)\end{array}$ \\
\hline $\begin{array}{l}\text { Median risk preference } \\
\text { (Investment task, standardized) }\end{array}$ & & $\begin{array}{c}0.027 \\
(0.042)\end{array}$ & & & $\begin{array}{c}0.005 \\
(0.040)\end{array}$ & & $\begin{array}{c}0.050 \\
(0.041)\end{array}$ \\
\hline $\begin{array}{l}\text { Median risk preferences } \\
\text { (Survey question, standardized) }\end{array}$ & & $\begin{array}{l}-0.010 \\
(0.044)\end{array}$ & & & $\begin{array}{c}0.001 \\
(0.046)\end{array}$ & & $\begin{array}{r}0.000 \\
(0.043\end{array}$ \\
\hline $\begin{array}{l}\text { Median SVO - Secondary } \\
\text { (egalitarian-efficiency, standardized) }\end{array}$ & & & $\begin{array}{l}-0.017 \\
(0.053)\end{array}$ & & $\begin{array}{c}-0.032 \\
(0.054)\end{array}$ & & $\begin{array}{c}0.014 \\
(0.061)\end{array}$ \\
\hline $\begin{array}{l}\text { Median Giving } \\
\text { (Survey question, standardized) }\end{array}$ & & & $\begin{array}{l}0.143^{* *} \\
(0.057)\end{array}$ & & $\begin{array}{l}0.161^{* * *} \\
(0.059)\end{array}$ & & $\begin{array}{l}0.160^{* * *} \\
(0.025)\end{array}$ \\
\hline $\begin{array}{l}\text { Median Competition } \\
(1=\text { competitive })\end{array}$ & & & & $\begin{array}{c}0.087 \\
(0.083)\end{array}$ & $\begin{array}{c}0.137 \\
(0.087)\end{array}$ & & $\begin{array}{l}0.146^{*} \\
(0.079)\end{array}$ \\
\hline Constant & $\begin{array}{l}-0.027 \\
(0.044) \\
\end{array}$ & $\begin{array}{l}-0.026 \\
(0.045) \\
\end{array}$ & $\begin{array}{c}0.021 \\
(0.047) \\
\end{array}$ & $\begin{array}{l}-0.038 \\
(0.044) \\
\end{array}$ & $\begin{array}{c}0.015 \\
(0.045) \\
\end{array}$ & $\begin{array}{c}0.325 \\
(0.276) \\
\end{array}$ & $\begin{array}{c}0.257 \\
(0.277) \\
\end{array}$ \\
\hline Observations & 830 & 830 & 830 & 830 & 830 & 830 & 415 \\
\hline R-squared & 0.171 & 0.176 & 0.235 & 0.181 & 0.259 & 0.208 & 0.299 \\
\hline
\end{tabular}

Estimates from linear regressions. Standard errors (clustered at the group level) in parentheses, ${ }^{* * *} \mathrm{p}<0.01,{ }^{* *} \mathrm{p}<0.05,{ }^{*} \mathrm{p}<0.1$. 
economic circumstances - requires better understanding.

To investigate this question, we design an experimental environment in which individuals repeatedly vote for redistribution policies and then engage in production subject to these policies. Consistent with evidence from outside the laboratory, women tend to vote for more egalitarian redistributive policies than men. This gap is substantial and persists with experience and is also very similar in environments with and without risk in the relationship between work and initial income.

We also replicate many previously observed gender gaps in more basic preferences. Women prefer less risk and less competition, prioritize equality over efficiency and report a greater willingness to share wealth. They are also less confident about their relative baseline performance in the task that we employ as the production activity, despite there being no gap in actual baseline performance. We then investigate the extent to which these gaps in basic preferences and expectations can account for the gender gap in voting. Our data suggest that preferences do play a role in voting behavior-particularly social preferences and competitiveness. However, differential expectations of future economic outcomes between men and women appear to have a larger impact on voting behavior. In combination, these two sets of factors go a long way in explaining the gender gap in policy preferences.

Finally, we also study whether the gender gap in policy preferences yields different policies enacted in groups where women, rather than men, hold the majority. We find this to be the case, but the magnitude and statistical strength of the group-level policy gaps is considerably smaller than the gaps at the individual level. Some of this naturally reflects a centralizing tendency of many social choice rules, including those like ours in which the median preferences have a large degree of impact.

Our work is important for better understanding how policies enacted in societies and organizations may change as women exert greater influence and control. First, our finding that expectations about relative performance appear to be a more important factor in explaining the gender gap in voting than gaps in more fundamental preferences indicates that the tendency for women to favor greater redistribution than men may diminish as women obtain better economic outcomes and security. Second, the relatively small policy gaps that we observe at the group level between male-dominated and female-dominated groups indicates that changes in policy outcomes from women exerting greater policy control may not be as dramatic as one might expect when extrapolating from average preference gaps at the individual level. Thus, claims that the world would be a fundamentally different place if women were to control policymaking should be tempered by the fact that such impacts may be relatively small. Our findings also 
provide an interpretation for why male- and female-majority groups often do not produce very different outcomes, despite the fact that gender differences in preferences seem quite reliable.

It is also worth noting that our evidence comes from contexts that we designed to create a straightforward relationship between the types of preferences often found to differ by gender and the unidimensional policy domain over which people vote. A natural open question is whether such differences persist in other contexts - for example, when the relationship between gender gaps in preferences for risk, competition and equality do not line up to predict concordant directional effects on policy preferences. Our work thus highlights the need for more careful study of precisely how gender differences scale up and persist over time to shape firms, institutions and societies.

\section{References}

Adams, Renée B. 2016. "Women on boards: The superheroes of tomorrow?" The Leadership Quarterly, Special Issue: Gender and Leadership, 27 (3): 371-86. https://doi.org/10.1016/j.leaqua.2015.11.001.

Adams, Renée B., and Patricia Funk. 2011. ”Beyond the Glass Ceiling: Does Gender Matter?” Management Science 58 (2): 219-35. https://doi.org/10.1287/mnsc.1110.1452.

Adams, Renee B., and Vanitha Ragunathan. 2017. "Lehman Sisters". SSRN Scholarly Paper ID 3046451. Rochester, NY: Social Science Research Network. https://papers.ssrn.com/abstract=3046451.

Agranov, Marina, and Thomas R. Palfrey. 2015. "Equilibrium tax rates and income redistribution: A laboratory study". Journal of Public Economics 130 (oktober): 45-58. https://doi.org/10.1016/j.jpubeco.2015.08.008.

Alesina, Alberto, and Paola Giuliano. 2009. "Preferences for Redistribution". NBER Working Paper 14825. NBER. http://www.nber.org/papers/w14825.

Almås, I., A. W. Cappelen, E. Ø. Sørensen, and B. Tungodden. 2010. "Fairness and the Development of Inequality Acceptance". Science 328 (5982): 1176-78. https://doi.org/10.1126/science.1187300.

Andreoni, J., and L. Vesterlund. 2001. "Which is the Fair Sex? Gender Differences in Altruism". The Quarterly Journal of Economics 116 (1): 293-312. https://doi.org/10.1162/003355301556419.

Barber, Brad M. \& Terrance. Odean. 2001. "Boys Will Be Boys: Gender, Overconfidence, and Common Stock Investment." The Quarterly Journal of Economics 116(1): 261-92. 
Bertrand, Marianne. 2011. "New Perspectives on Gender". I Handbook of Labor Economics, 4:1543-90. Elsevier. http://linkinghub.elsevier.com/retrieve/pii/S0169721811024154.

Bilén, David and Dreber, Anna and Johanneson, Magnus, Are Women More Generous Than Men? A Meta-Analysis (April 16, 2020). Available at SSRN: https://ssrn.com/abstract=3578038 or http://dx.doi.org/10.2139/ssrn.3578038

Bock, Olaf, Ingmar Baetge, and Andreas Nicklisch. 2014. "hroot: Hamburg Registration and Organization Online Tool". European Economic Review 71 (oktober): 117-20. https://doi.org/10.1016/j.euroecorev.2014.07.003.

Buser, Thomas, Gianluca Grimalda, Louis Putterman, and Joël van der Weele. 2020. "Overconfidence and Gender Gaps in Redistributive Preferences: Cross-Country Experimental Evidence." Journal of Economic Behavior \& Organization 178 (October): 267-86. https://doi.org/10.1016/j.jebo.2020.07.005.

Bagues, Manuel, and Pamela Campa. 2021. "Can Gender Quotas in Candidate Lists Empower Women? Evidence from a Regression Discontinuity Design." Journal of Public Economics 194 (February): 104315. https://doi.org/10.1016/j.jpubeco.2020.104315.

Cárdenas, Juan-Camilo, Anna Dreber, Emma von Essen, and Eva Ranehill. 2012. "Gender differences in competitiveness and risk taking: Comparing children in Colombia and Sweden". Journal of Economic Behavior \& Organization, Gender Differences in Risk Aversion and Competition, 83 (1): 11-23. https://doi.org/10.1016/j.jebo.2011.06.008.

Cason, Timothy N., William A. Masters, and Roman M. Sheremeta. 2010. ’Entry into winnertake-all and proportional-prize contests: An experimental study". Journal of Public Economics 94 (9-10): 604-11. https://doi.org/10.1016/j.jpubeco.2010.05.006.

Chattopadhyay, Raghabendra, and Esther Duflo. 2004. "Women as Policy Makers: Evidence from a Randomized Policy Experiment in India". Econometrica 72 (5): 1409-43. https://doi.org/10.1111/j.1468-0262.2004.00539.x.

Croson, Rachel, and Uri Gneezy. 2009. "Gender Differences in Preferences". Journal of Economic Literature 47 (2): 448-74. https://doi.org/10.1257/jel.47.2.448.

Dohmen, Thomas, Armin Falk, David Huffman, Uwe Sunde, Jürgen Schupp, and Gert G. Wagner. 2011. 'Individual Risk Attitudes: Measurement, Determinants, and Behavioral Consequences". Journal of the European Economic Association 9 (3): 522-50. https://doi.org/10.1111/j.1542-4774.2011.01015.x.

Dreber, Anna, Emma Essen, and Eva Ranehill. 2014. "Gender and Competition in Adolescence: Task Matters". Experimental Economics 17 (1): 154-72. https://doi.org/10.1007/s10683-013-9361-0. 
Eckbo, B. Espen, Knut Nygaard, and Karin S. Thorburn. 2016. "How Costly Is Forced GenderBalancing of Corporate Boards?" SSRN Scholarly Paper ID 2746786. Rochester, NY: Social Science Research Network. https://papers.ssrn.com/abstract=2746786.

Eckel, Catherine C., and Philip J. Grossman. 2008. "Men, women and risk aversion: Experimental evidence". In Handbook of Experimental Economics Results, 7:1061-73. 1.

Edlund, L., and R. Pande. 2002. "Why Have Women Become Left-Wing? The Political Gender Gap and the Decline in Marriage". The Quarterly Journal of Economics 117 (3): 917-61. https://doi.org/10.1162/003355302760193922.

Engel, Christoph. 2011. "Dictator Games: A Meta Study”. Experimental Economics 14 (4): 583-610. https://doi.org/10.1007/s10683-011-9283-7.

Erkal, Nisvan, Lata Gangadharan, and Nikos Nikiforakis. 2011. "Relative Earnings and Giving in a Real-Effort Experiment". American Economic Review 101 (7): 3330-48. https://doi.org/10.1257/aer.101.7.3330.

Ertac, Seda, and Balazs Szentes. 2011. "The Effect of Information on Gender Differences in Competitiveness: Experimental Evidence”. Koç University-TUSIAD Economic Research Forum Working Paper 1104. Koc University-TUSIAD Economic Research Forum. https://ideas.repec.org/p/koc/wpaper/1104.html.

Falk, Armin, and Johannes Hermle. 2018. "Relationship of Gender Differences in Preferences to Economic Development and Gender Equality". Science 362 (6412): eaas9899. https://doi.org/10.1126/science.aas9899.

Filippin, Antonio and Paole Crosetto. 2016. "A Reconsideration of Gender Differences in Risk Attitudes". Management Science, februari. https://doi.org/10.1287/mnsc.2015.2294.

Fischbacher, Urs. 2007. "Z-Tree: Zurich Toolbox for Ready-Made Economic Experiments". Experimental Economics 10 (2): 171-78. https://doi.org/10.1007/s10683-006-9159-4.

Fisman, Raymond, Pamela Jakiela, and Shachar Kariv. 2014. "The Distributional Preferences of Americans". Working Paper 20145. National Bureau of Economic Research. http://www.nber.org/papers/w20145.

- 2017. "Distributional preferences and political behavior". Journal of Public Economics 155 (november): 1-10. https://doi.org/10.1016/j.jpubeco.2017.08.010.

Funk, Patricia, and Christina Gathmann. 2015. "Gender Gaps in Policy Making: Evidence from Direct Democracy in Switzerland". Economic Policy 30 (81): 141-81. https://doi.org/10.1093/epolic/eiu003.

Gneezy, Uri, and Jan Potters. 1997. "An Experiment on Risk Taking and Evaluation Periods". The Quarterly Journal of Economics 112 (2): 631-45. 
Grosse, Niels, Gerhard Riener, and Markus Dertwinkel-Kalt. 2014. "Explaining Gender Differences in Competitiveness: Testing a Theory on Gender-Task Stereotypes". SSRN Scholarly Paper ID 2551206. Rochester, NY: Social Science Research Network. http://papers.ssrn.com/abstract=2551206.

Günther, Christina, Neslihan Arslan Ekinci, Christiane Schwieren, and Martin Strobel. 2010. "Women Can't Jump? — An Experiment on Competitive Attitudes and Stereotype Threat". Journal of Economic Behavior \& Organization 75 (3): 395-401. https://doi.org/10.1016/j.jebo.2010.05.003.

Gächter, Simon, and Elke Renner. 2010. "The Effects of (Incentivized) Belief Elicitation in Public Goods Experiments”. Experimental Economics 13 (3): 364-77. https://doi.org/10.1007/s10683-010-9246-4.

Gärtner, Manja, Johanna Mollerstrom, and David Seim. 2017. 'Individual risk preferences and the demand for redistribution". Journal of Public Economics 153 (september): 49-55. https://doi.org/10.1016/j.jpubeco.2017.06.009.

Hessami, Zohal, and Mariana Lopes da Fonseca. 2020. "Female Political Representation and Substantive Effects on Policies: A Literature Review.” European Journal of Political Economy 63 (June): 101896. https://doi.org/10.1016/j.ejpoleco.2020.101896.

Iriberri, Nagore, and Pedro Rey-Biel. 2011. "Let's (not) talk about sex: The effect of information provision on gender differences in performance under competition". Barcelona: Universitat Pompeu Fabra. Department d' Economia i Empresa. http://hdl.handle.net/10230/19894.

Lundeberg, Mary, Paul W. Fox \& Judith Punćcohaŕ. 1994. "Highly Confident but Wrong: Gender Differences and Similarities in Confidence Judgments.” Journal of Educational Psychology 86(1): 114-21.

Matsa, David A, and Amalia R Miller. 2013. "A Female Style in Corporate Leadership? Evidence from Quotas". American Economic Journal: Applied Economics 5 (3): 136-69. https://doi.org/10.1257/app.5.3.136.

Murphy, R. O., K.A. Ackermann, and M. J. J Handgraaf. 2011. ”Measuring Social Value Orientation". Judgment and Decision Making 6 (8): 771-81.

Nelson, Julie A. 2015. “Are Women Really More Risk-Averse Than Men? A Re-Analysis of the Literature Using Expanded Methods." Journal of Economic Surveys 29 (3): 566-85. https://doi.org/10.1111/joes.12069.

Niederle, Muriel, “Gender” Handbook of Experimental Economics, second edition, Eds. John Kagel and Alvin E. Roth, Princeton University Press, 2016, 481-553. 
Niederle, M., and L. Vesterlund. 2007. ”Do Women Shy Away From Competition? Do Men Compete Too Much?" The Quarterly Journal of Economics 122 (3): 1067-1101. https://doi.org/10.1162/qjec.122.3.1067.

Niederle, Muriel, and Lise Vesterlund. 2010. "Explaining the Gender Gap in Math Test Scores: The Role of Competition". Journal of Economic Perspectives 24 (2): 129-44. https://doi.org/10.1257/jep.24.2.129.

Price, Curtis R. 2011. "Gender, Competition, and Managerial Decisions". Management Science 58 (1): 114-22. https://doi.org/10.1287/mnsc.1110.1384.

Shurchkov, Olga. 2012. "Under Pressure: Gender Differences in Output Quality and Quantity Under Competition and Time Constraints". Journal of the European Economic Association 10 (5): 1189-1213. https://doi.org/10.1111/j.1542-4774.2012.01084.x.

Shurchkov, Olga, and Alexandra V. M. van Geen. 2019. "Why Female Decision-Makers Shy Away from Promoting Competition." Kyklos 72 (2): 297-331. https://doi.org/10.1111/kykl.12202.

Sutter, Matthias, F. Feri, M. G. Kocher, P. Martinsson, K. Nordblom, and D. Rützler. 2010. "Social preferences in childhood and adolescence - A large-scale experiment". Working Paper 2010-2013. Economics and Statistics. University of Innsbruck. http://www.econstor.eu/bitstream/10419/73533/1/744075823.pdf.

Wechsler, David. 1958. The Measurement And Appraisal Of Adult Intelligence. The Williams \& Wilkins Company. http://archive.org/details/measurementandap001570mbp.

Wozniak, David, William T. Harbaugh, and Ulrich Mayr. 2014. "The Menstrual Cycle and Performance Feedback Alter Gender Differences in Competitive Choices". Journal of Labor Economics 32 (1): 161-98. https://doi.org/10.1086/673324. 
Online Appendix Ranehill Weber 2021

Table OA1: Relationships between preferences and performance beliefs on first-period votes

Dependent variable:

Vote in Period 1

\begin{tabular}{|c|c|c|c|c|c|c|c|c|c|c|}
\hline & \multicolumn{8}{|c|}{ All } & \multirow{2}{*}{$\begin{array}{c}\text { Male } \\
(9)\end{array}$} & \multirow{2}{*}{$\begin{array}{c}\text { Female } \\
(10)\end{array}$} \\
\hline & (1) & (2) & (3) & (4) & (5) & (6) & (7) & (8) & & \\
\hline Female & $\begin{array}{l}0.190^{* * *} \\
(0.049)\end{array}$ & $\begin{array}{l}0.177^{* * *} \\
(0.048)\end{array}$ & $\begin{array}{l}0.189^{* * *} \\
(0.047)\end{array}$ & $\begin{array}{l}0.166^{* * *} \\
(0.047)\end{array}$ & $\begin{array}{l}0.183^{* * *} \\
(0.047)\end{array}$ & $\begin{array}{l}0.161^{* * *} \\
(0.050)\end{array}$ & $\begin{array}{l}0.122^{* *} \\
(0.049)\end{array}$ & $\begin{array}{l}0.186^{* * *} \\
(0.049)\end{array}$ & & \\
\hline Risk condition & $\begin{array}{c}0.136^{* * *} \\
(0.049)\end{array}$ & $\begin{array}{c}0.142^{* * *} \\
(0.049)\end{array}$ & $\begin{array}{l}0.123^{* *} \\
(0.049)\end{array}$ & $\begin{array}{c}0.136^{* * *} \\
(0.048)\end{array}$ & $\begin{array}{c}0.133^{* * *} \\
(0.048)\end{array}$ & $\begin{array}{c}0.135^{* * *} \\
(0.048)\end{array}$ & $\begin{array}{l}0.105^{* *} \\
(0.047)\end{array}$ & $\begin{array}{l}0.132^{* * *} \\
(0.048)\end{array}$ & $\begin{array}{l}0.116^{*} \\
(0.069)\end{array}$ & $\begin{array}{c}0.072 \\
(0.067)\end{array}$ \\
\hline $\begin{array}{l}\text { Risk preferences } \\
\text { (Investment task, standardized) }\end{array}$ & $\begin{array}{l}-0.011 \\
(0.023)\end{array}$ & & & & & & & & $\begin{array}{c}0.007 \\
(0.038)\end{array}$ & $\begin{array}{c}0.013 \\
(0.036)\end{array}$ \\
\hline $\begin{array}{l}\text { Risk preferences } \\
\text { (Survey question, standardized) }\end{array}$ & & $\begin{array}{l}-0.040 \\
(0.026)\end{array}$ & & & & & & & $\begin{array}{l}-0.056 \\
(0.038)\end{array}$ & $\begin{array}{l}-0.021 \\
(0.037)\end{array}$ \\
\hline $\begin{array}{l}\text { Social Value Orientation - Primary } \\
\text { (competitive-altruistic, standardized) }\end{array}$ & & & $\begin{array}{l}0.083^{* * *} \\
(0.025)\end{array}$ & & & & & & $\begin{array}{c}0.024 \\
(0.044)\end{array}$ & $\begin{array}{l}0.107^{* * *} \\
(0.032)\end{array}$ \\
\hline $\begin{array}{l}\text { Social Value Orientation - Secondary } \\
\text { (egalitarian-efficiency, standardized) }\end{array}$ & & & & $\begin{array}{c}-0.075^{* * *} \\
(0.019)\end{array}$ & & & & & $\begin{array}{l}-0.018 \\
(0.033)\end{array}$ & $\begin{array}{l}-0.060 \\
(0.037)\end{array}$ \\
\hline $\begin{array}{l}\text { Giving } \\
\text { (Survey question, standardized) }\end{array}$ & & & & & $\begin{array}{c}0.033 \\
(0.022)\end{array}$ & & & & $\begin{array}{c}0.037 \\
(0.030)\end{array}$ & $\begin{array}{l}-0.008 \\
(0.037)\end{array}$ \\
\hline $\begin{array}{l}\text { Competition } \\
(1=\text { competitive })\end{array}$ & & & & & & $\begin{array}{c}-0.129^{* * *} \\
(0.050)\end{array}$ & & & $\begin{array}{l}-0.022 \\
(0.067)\end{array}$ & $\begin{array}{l}-0.067 \\
(0.090)\end{array}$ \\
\hline $\begin{array}{l}\text { Relative performance beliefs } \\
\text { (standardized) }\end{array}$ & & & & & & & $\begin{array}{c}-0.144^{* * *} \\
(0.024)\end{array}$ & & $\begin{array}{c}-0.135^{* * *} \\
(0.036)\end{array}$ & $\begin{array}{c}-0.112^{* * *} \\
(0.034)\end{array}$ \\
\hline $\begin{array}{l}\text { Part } 2 \text { task performance } \\
\text { (standardized) }\end{array}$ & & & & & & & & $\begin{array}{c}-0.058^{* *} \\
(0.023)\end{array}$ & $\begin{array}{l}-0.045 \\
(0.028)\end{array}$ & $\begin{array}{c}0.019 \\
(0.031)\end{array}$ \\
\hline Constant & $\begin{array}{l}-0.049 \\
(0.035)\end{array}$ & $\begin{array}{l}-0.044 \\
(0.035)\end{array}$ & $\begin{array}{l}-0.040 \\
(0.035)\end{array}$ & $\begin{array}{l}-0.036 \\
(0.035)\end{array}$ & $\begin{array}{l}-0.042 \\
(0.035)\end{array}$ & $\begin{array}{c}0.006 \\
(0.040)\end{array}$ & $\begin{array}{c}0.001 \\
(0.035)\end{array}$ & $\begin{array}{l}-0.043 \\
(0.035)\end{array}$ & $\begin{array}{c}0.028 \\
(0.046)\end{array}$ & $\begin{array}{c}0.144^{* * *} \\
(0.051)\end{array}$ \\
\hline Observations & 415 & 415 & 415 & 415 & 415 & 415 & 415 & 415 & 218 & 197 \\
\hline R-squared & 0.063 & 0.069 & 0.091 & 0.085 & 0.067 & 0.076 & 0.144 & 0.077 & 0.158 & 0.185 \\
\hline
\end{tabular}

Estimates from linear regressions. Standard errors (clustered at the group level) in parentheses, ${ }^{* * *} \mathrm{p}<0.01,{ }^{* *} \mathrm{p}<0.05,{ }^{*} \mathrm{p}<0.1$. 
Table OA2: Correlations between vote in Period 1 and individual characteristics

\begin{tabular}{|c|c|c|c|c|c|c|}
\hline & \multicolumn{3}{|c|}{ No Risk } & \multicolumn{3}{|c|}{ Risk } \\
\hline & All & Male & Female & All & Male & Female \\
\hline $\begin{array}{l}\text { Risk }(\text { Investment task) } \\
\text { (incentivized } 0-100,100=\text { risky) }\end{array}$ & $\begin{array}{l}-0.143 \\
(0.043)\end{array}$ & $\begin{array}{l}-0.147 \\
(0.130)\end{array}$ & $\begin{array}{l}-0.020 \\
(0.852)\end{array}$ & $\begin{array}{l}-0.011 \\
(0.877)\end{array}$ & $\begin{array}{c}0.057 \\
(0.556)\end{array}$ & $\begin{array}{c}0.018 \\
(0.860)\end{array}$ \\
\hline $\begin{array}{l}\text { Risk (Survey question) } \\
\text { (non-incentivized } 0-10,10=\text { risk taking) }\end{array}$ & $\begin{array}{l}-0.215 \\
(0.002)\end{array}$ & $\begin{array}{l}-\mathbf{- 0 . 2 9 7} \\
(\mathbf{0 . 0 0 2 )}\end{array}$ & $\begin{array}{c}0.006 \\
(0.956)\end{array}$ & $\begin{array}{l}-0.051 \\
(0.461)\end{array}$ & $\begin{array}{c}0.050 \\
(0.603)\end{array}$ & $\begin{array}{l}-0.092 \\
(0.353)\end{array}$ \\
\hline $\begin{array}{l}\text { Social Value Orientation (Primary) } \\
\text { (Incentivized, }-45=\text { competitive; } 90=\text { altruistic) }\end{array}$ & $\begin{array}{l}0.181 \\
(0.011)\end{array}$ & $\begin{array}{c}0.062 \\
(0.524)\end{array}$ & $\begin{array}{c}0.293 \\
(0.004)\end{array}$ & $\begin{array}{c}0.181 \\
(0.008)\end{array}$ & $\begin{array}{c}0.048 \\
(0.614)\end{array}$ & $\begin{array}{c}0.347 \\
(<0.001)\end{array}$ \\
\hline $\begin{array}{l}\text { Social Value Orientation (Secondary) } \\
\text { (Incentivized, } 0=\text { egalitarian; } 1=\text { efficiency) }\end{array}$ & $\begin{array}{c}-0.243 \\
(0.001)\end{array}$ & $\begin{array}{l}-0.169 \\
(0.082)\end{array}$ & $\begin{array}{l}-0.239 \\
(0.021)\end{array}$ & $\begin{array}{l}-0.161 \\
(0.018)\end{array}$ & $\begin{array}{l}-0.024 \\
(0.803)\end{array}$ & $\begin{array}{r}-0.264 \\
(0.007)\end{array}$ \\
\hline $\begin{array}{l}\text { Giving (Survey question) } \\
\text { (non-incentivized, } 0-1000,1000=\text { generous) }\end{array}$ & $\begin{array}{c}0.104 \\
(0.142)\end{array}$ & $\begin{array}{c}0.038 \\
(0.701)\end{array}$ & $\begin{array}{c}0.015 \\
(0.886)\end{array}$ & $\begin{array}{c}0.108 \\
(0.115)\end{array}$ & $\begin{array}{c}0.115 \\
(0.231)\end{array}$ & $\begin{array}{c}0.066 \\
(0.504)\end{array}$ \\
\hline $\begin{array}{l}\text { Competitiveness } \\
(0 \text { or } 1,1=\text { competitive })\end{array}$ & $\begin{array}{c}-0.232 \\
(0.001)\end{array}$ & $\begin{array}{l}-0.239 \\
(0.013)\end{array}$ & $\begin{array}{l}-0.033 \\
(0.757)\end{array}$ & $\begin{array}{l}-0.124 \\
(0.070)\end{array}$ & $\begin{array}{l}-0.068 \\
(0.478)\end{array}$ & $\begin{array}{l}-0.111 \\
(0.263)\end{array}$ \\
\hline $\begin{array}{l}\text { Relative performance beliefs } \\
\text { (guessed rank: } 0=\text { worst; } 100=\text { best) }\end{array}$ & $\begin{array}{c}-0.394 \\
(<0.001)\end{array}$ & $\begin{array}{c}-\mathbf{0 . 4 8 0} \\
(<\mathbf{0 . 0 0 1})\end{array}$ & $\begin{array}{l}-0.161 \\
(0.122)\end{array}$ & $\begin{array}{c}-0.283 \\
(<0.001)\end{array}$ & $\begin{array}{l}-0.194 \\
(0.041)\end{array}$ & $\begin{array}{r}-\mathbf{- 0 . 3 3 7} \\
(\mathbf{0 . 0 0 1 )}\end{array}$ \\
\hline $\begin{array}{l}\text { Average performance } \\
\text { (Initial piece rate in Part 2) }\end{array}$ & $\begin{array}{l}-0.171 \\
(0.015)\end{array}$ & $\begin{array}{l}-0.178 \\
(0.067)\end{array}$ & $\begin{array}{l}-0.060 \\
(0.567)\end{array}$ & $\begin{array}{l}-0.108 \\
(0.114)\end{array}$ & $\begin{array}{l}-0.159 \\
(0.095)\end{array}$ & $\begin{array}{l}-0.050 \\
(0.618)\end{array}$ \\
\hline Observations & 200 & 107 & 93 & 215 & 111 & 104 \\
\hline
\end{tabular}

Each cell reports the correlation between the corresponding individual-level measure and Period 1 vote. Italics: $\mathrm{p}<0.05$; bold: $\mathrm{p}<0.01$. 
Table OA3: The impact of preferences and performance beliefs on votes in Periods 2-10

Dependent variable:

Vote

\begin{tabular}{|c|c|c|c|c|c|}
\hline & \multicolumn{3}{|c|}{ Periods } & \multicolumn{2}{|c|}{ Periods 2-10 } \\
\hline & $\begin{array}{l}2-4 \\
(1) \\
\end{array}$ & $\begin{array}{l}5-7 \\
(2)\end{array}$ & $\begin{array}{l}8-10 \\
(3)\end{array}$ & $\begin{array}{c}\text { No Risk } \\
\text { (4) }\end{array}$ & $\begin{array}{c}\text { Risk } \\
(5)\end{array}$ \\
\hline Female & $\begin{array}{c}0.052 \\
(0.048)\end{array}$ & $\begin{array}{c}0.055 \\
(0.055)\end{array}$ & $\begin{array}{c}0.092 \\
(0.057)\end{array}$ & $\begin{array}{c}0.060 \\
(0.061)\end{array}$ & $\begin{array}{c}0.096 \\
(0.072)\end{array}$ \\
\hline Risk condition & $\begin{array}{c}0.187^{* * *} \\
(0.044)\end{array}$ & $\begin{array}{c}0.171^{* * *} \\
(0.048)\end{array}$ & $\begin{array}{c}0.117^{* * *} \\
(0.048)\end{array}$ & & \\
\hline $\begin{array}{l}\text { Risk preferences } \\
\text { (Investment task, standardized) }\end{array}$ & $\begin{array}{c}0.005 \\
(0.025)\end{array}$ & $\begin{array}{c}0.042 \\
(0.034)\end{array}$ & $\begin{array}{c}0.010 \\
(0.031)\end{array}$ & $\begin{array}{l}-0.014 \\
(0.037)\end{array}$ & $\begin{array}{c}0.059 \\
(0.037)\end{array}$ \\
\hline $\begin{array}{l}\text { Risk preferences } \\
\text { (Survey question, standardized) }\end{array}$ & $\begin{array}{l}-0.012 \\
(0.022)\end{array}$ & $\begin{array}{l}-0.021 \\
(0.029)\end{array}$ & $\begin{array}{l}-0.020 \\
(0.027)\end{array}$ & $\begin{array}{l}-0.003 \\
(0.031)\end{array}$ & $\begin{array}{l}-0.033 \\
(0.037)\end{array}$ \\
\hline $\begin{array}{l}\text { Social Value Orientation - Primary } \\
\text { (competitive-altruistic, standardized) }\end{array}$ & $\begin{array}{c}0.014 \\
(0.023)\end{array}$ & $\begin{array}{c}0.027 \\
(0.033)\end{array}$ & $\begin{array}{c}0.060^{*} \\
(0.033)\end{array}$ & $\begin{array}{c}0.049 \\
(0.045)\end{array}$ & $\begin{array}{c}0.028 \\
(0.034)\end{array}$ \\
\hline $\begin{array}{l}\text { Social Value Orientation - Secondary } \\
\text { (egalitarian-efficiency, standardized) }\end{array}$ & $\begin{array}{l}-0.026 \\
(0.024)\end{array}$ & $\begin{array}{l}-0.011 \\
(0.028)\end{array}$ & $\begin{array}{l}-0.022 \\
(0.024)\end{array}$ & $\begin{array}{c}0.006 \\
(0.034)\end{array}$ & $\begin{array}{l}-0.026 \\
(0.028)\end{array}$ \\
\hline $\begin{array}{l}\text { Giving } \\
\text { (Survey question, standardized) }\end{array}$ & $\begin{array}{c}0.002 \\
(0.021)\end{array}$ & $\begin{array}{c}0.013 \\
(0.028)\end{array}$ & $\begin{array}{l}-0.048^{*} \\
(0.028)\end{array}$ & $\begin{array}{l}-0.056^{*} \\
(0.023)\end{array}$ & $\begin{array}{c}0.021 \\
(0.030)\end{array}$ \\
\hline $\begin{array}{l}\text { Competition } \\
(1=\text { competitive })\end{array}$ & $\begin{array}{l}-0.091^{*} \\
(0.050)\end{array}$ & $\begin{array}{l}-0.059 \\
(0.064)\end{array}$ & $\begin{array}{l}-0.041 \\
(0.062)\end{array}$ & $\begin{array}{l}-0.072 \\
(0.075)\end{array}$ & $\begin{array}{l}-0.069 \\
(0.075)\end{array}$ \\
\hline $\begin{array}{l}\text { Relative Part } 2 \text { performance beliefs } \\
\text { (standardized) }\end{array}$ & $\begin{array}{c}-0.074^{* * *} \\
(0.022)\end{array}$ & $\begin{array}{l}-0.121^{* * *} \\
(0.027)\end{array}$ & $\begin{array}{c}-0.108^{* * *} \\
(0.028)\end{array}$ & $\begin{array}{c}-0.123^{* * *} \\
(0.035)\end{array}$ & $\begin{array}{c}-0.099^{* * *} \\
(0.030)\end{array}$ \\
\hline $\begin{array}{l}\text { Lagged relative performance } \\
\text { (standardized) }\end{array}$ & $\begin{array}{c}-0.228^{* * *} \\
(0.021)\end{array}$ & $\begin{array}{c}-0.178^{* * *} \\
(0.022)\end{array}$ & $\begin{array}{c}-0.219^{* * *} \\
(0.023)\end{array}$ & $\begin{array}{l}-0.231^{* * *} \\
(0.024)\end{array}$ & $\begin{array}{c}-0.120^{* * *} \\
(0.018)\end{array}$ \\
\hline Constant & $\begin{array}{c}0.014 \\
(0.041)\end{array}$ & $\begin{array}{l}-0.005 \\
(0.045)\end{array}$ & $\begin{array}{c}0.000 \\
(0.043)\end{array}$ & $\begin{array}{c}0.008 \\
(0.048)\end{array}$ & $\begin{array}{l}0.145^{* *} \\
(0.058)\end{array}$ \\
\hline Observations & 1,245 & 1,245 & 1,245 & 1,800 & 1,935 \\
\hline R-squared & 0.384 & 0.331 & 0.378 & 0.526 & 0.267 \\
\hline
\end{tabular}

Estimates from linear regressions with random effects at the subject level. Robust standard errors in parentheses, ${ }^{* * *} \mathrm{p}<0.01,{ }^{* *} \mathrm{p}<0.05,{ }^{*} \mathrm{p}<0.1$. 


\section{Figure OA1: An example of policy gaps as a function of individual preference gaps}

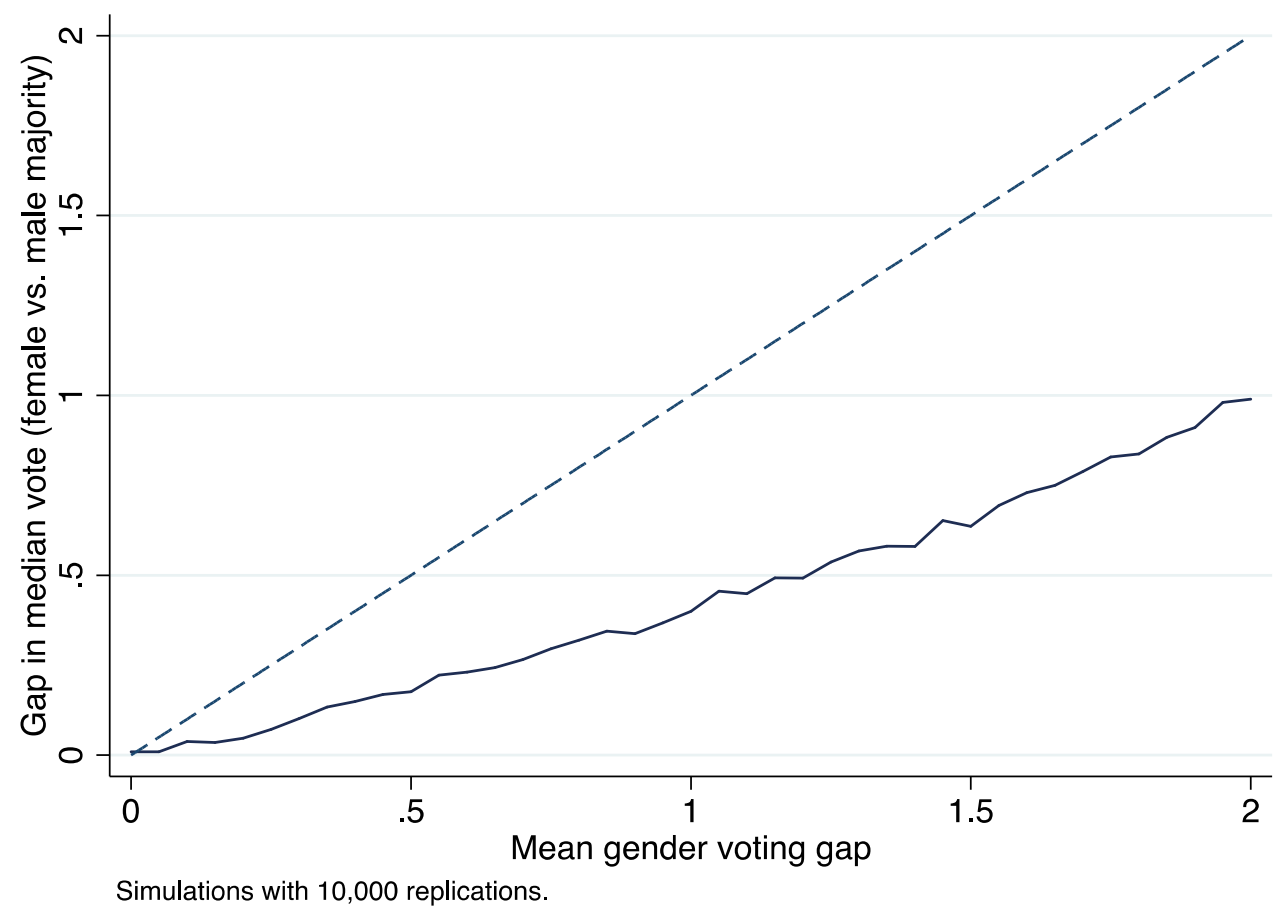

In the simulation analysis presented above, we assume that men's preferences are distributed according to a normal distribution, $v^{m} \sim N(0,1)$, and that women's preferences are distributed similarly but with a different mean, $v^{f} \sim N(\theta, 1)$. Our simulations construct five-person groups at random, classify them as majority male or majority female, and then identify the group's median preference. This simple stylized example of a group making a collective choice parallels our experiment's design. In the graph, the horizontal axis shows the mean gender preference gap, $\theta$, while the vertical axis presents the mean difference in implemented policies between majority-male and majority-female groups 
Figure OA2: Cumulative distributions of first-period votes by gender and condition

A. No Risk condition

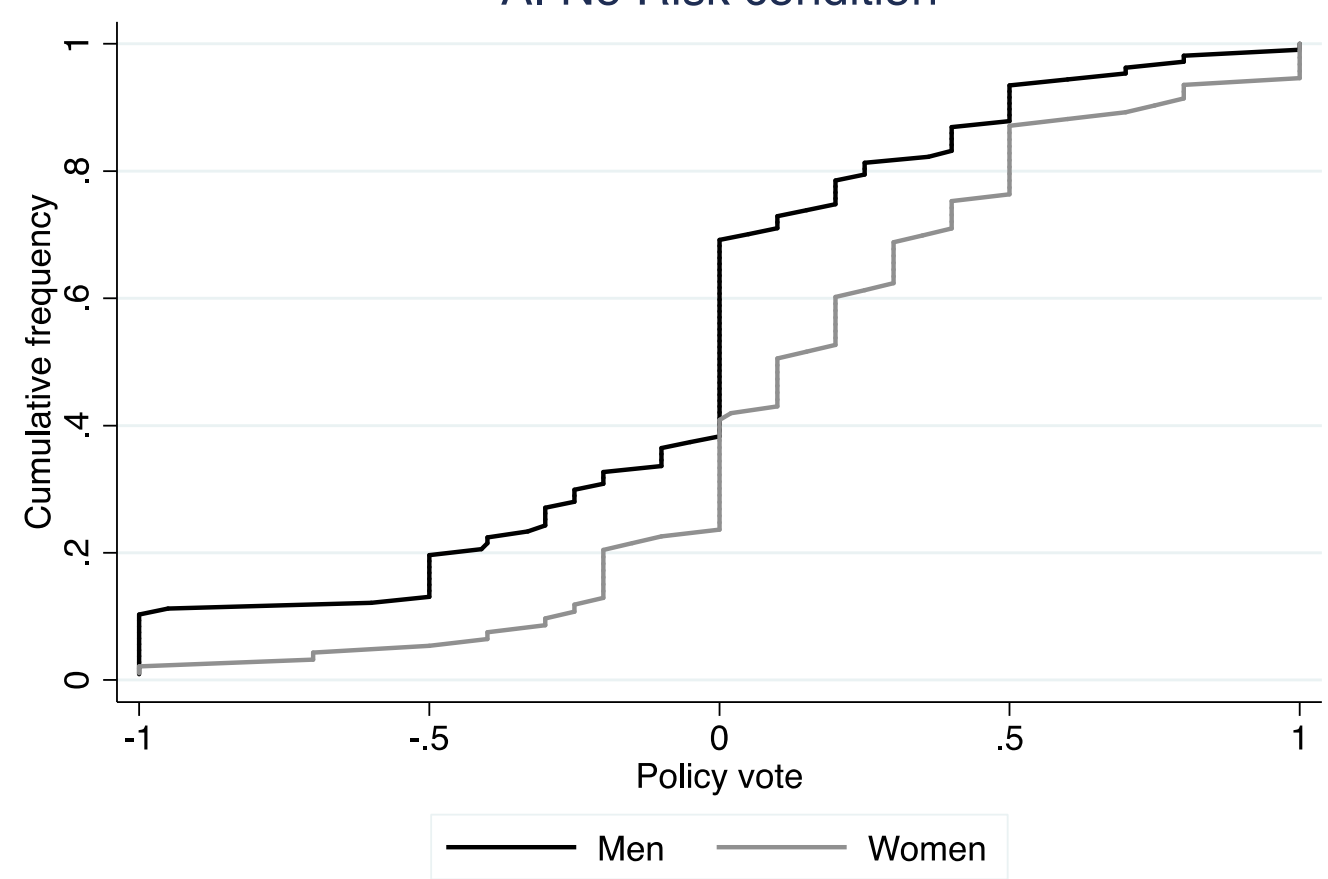

B. Risk condition

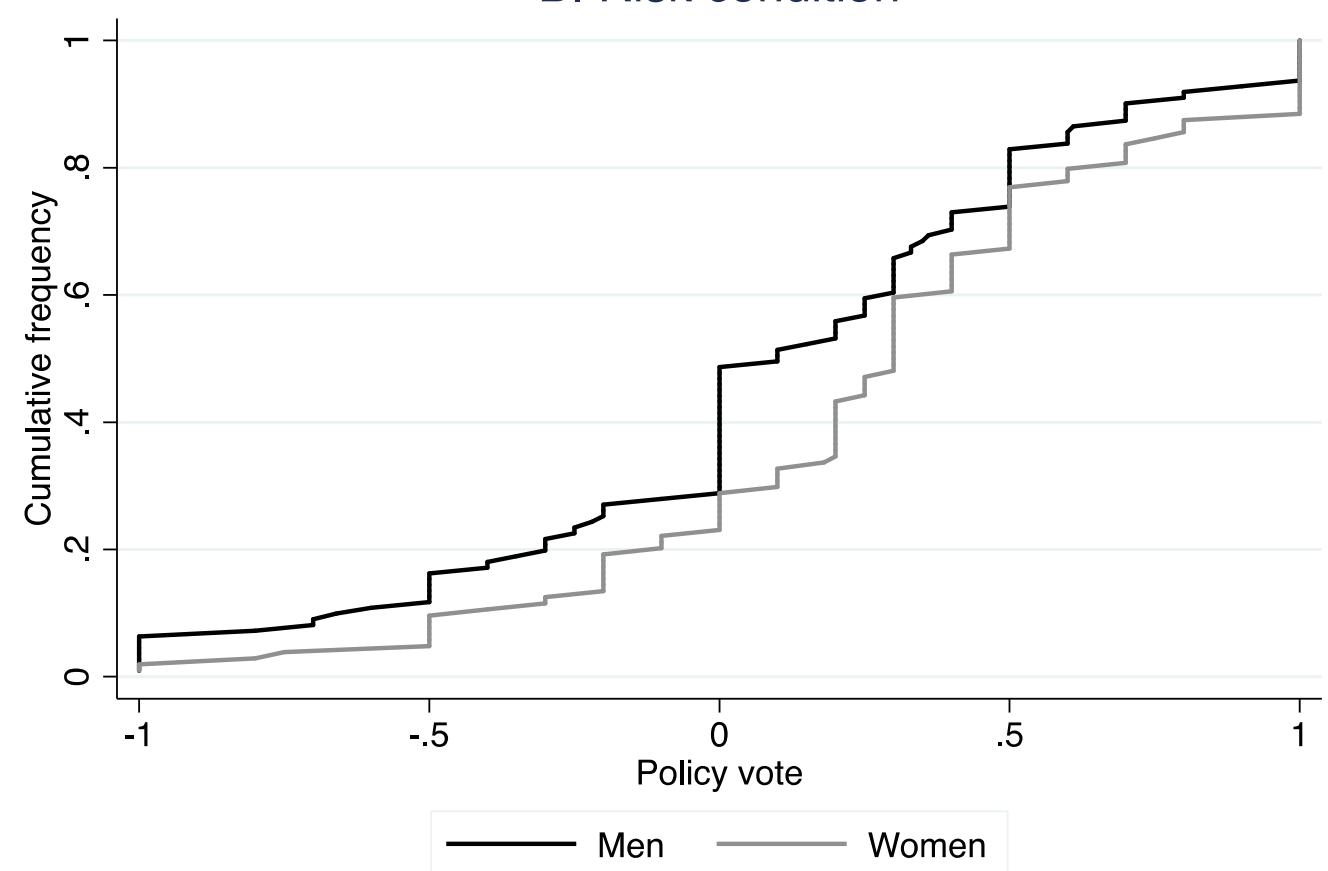


Figure OA3. Performance in task over time

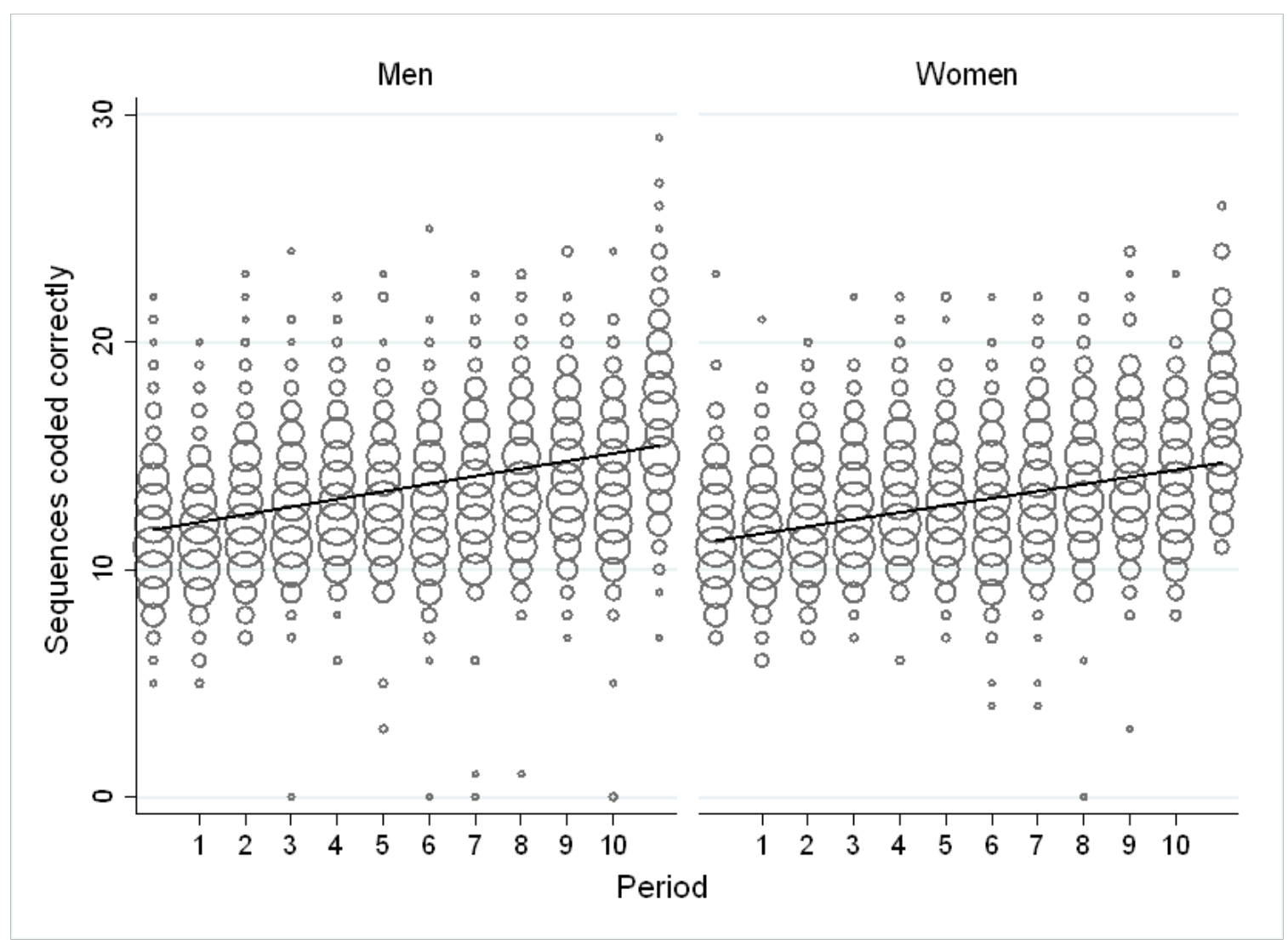


Figure A4. Comparison of votes (first vs. second half of Stage 3)

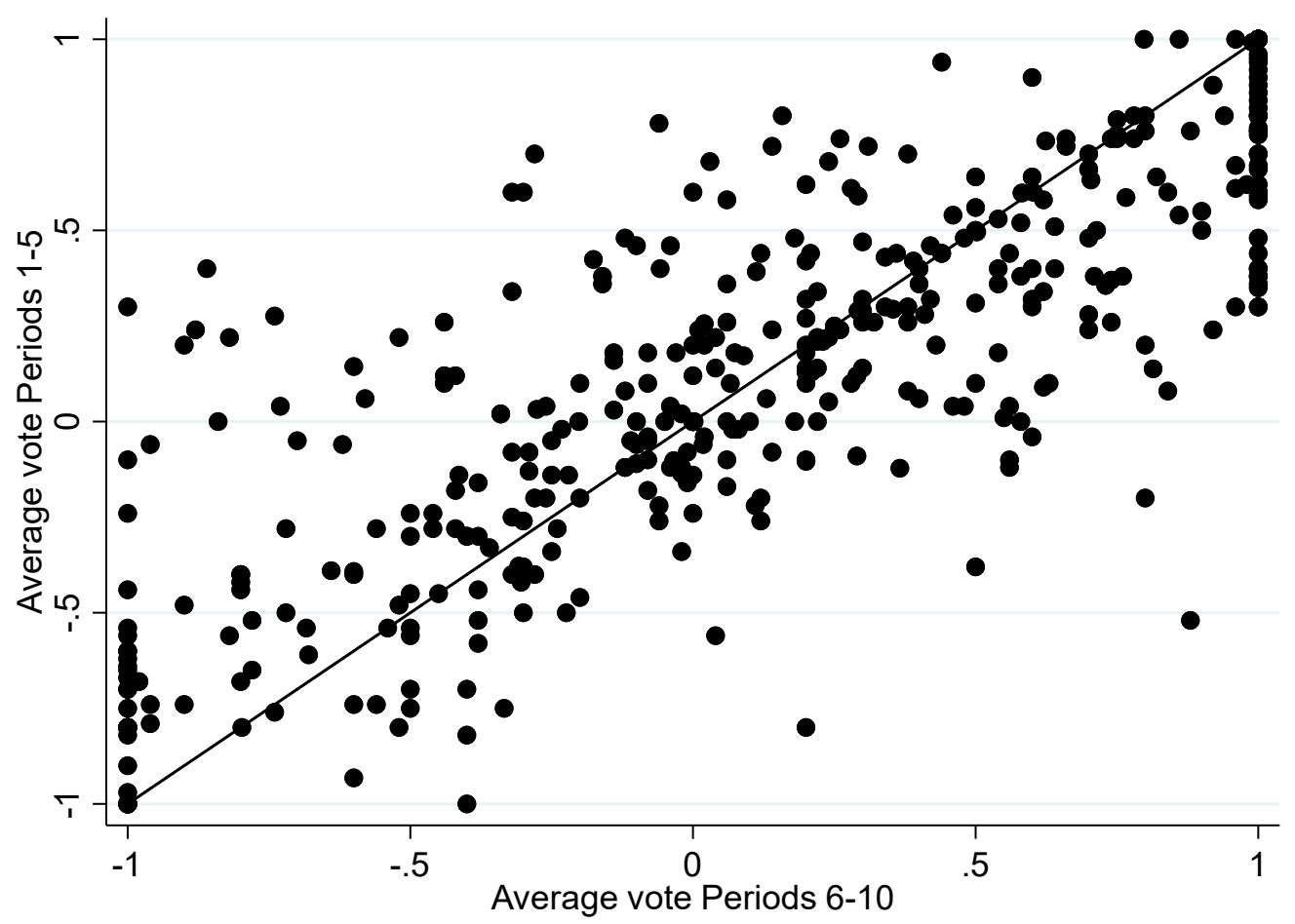




\section{Appendix B : Instructions}

\section{Initial Instructions}

The experiment comprises three parts. We will provide you with detailed instructions before each part.

In addition to the CHF 10 payment that you receive for your participation, you will be paid an additional amount of money that you accumulate from decision tasks in the three parts of the study. The exact amount you receive will be determined during the experiment, and will depend on your decisions, and the decisions of others. Please note that the decisions you make in any part of the experiment will have no effect on what happens in other parts.

All monetary amounts you will see in this experiment will be denominated in experimental currency units (ECU). At the end of the experiment, your earnings in ECU will be exchanged into CHF at a rate of

\section{$50 \mathrm{ECU}=1 \mathrm{CHF}$}

Note that all your interactions in the study are anonymous. This means that you will not know the identity of any other participant with whom you interact and no other participants will know your identity.

If you have any questions during the experiment, please raise your hand and wait for an experimenter to come to you. Please do not talk, exclaim, or try to communicate with other participants during the experiment. Participants intentionally violating the rules may be asked to leave the experiment with only their participation payment.

Please click "Continue" now to see the instructions for the first part of the study. 


\section{Instructions to Part 1}

In Part 1 you will make a few simple economic decisions and answer some questions. You will receive detailed instructions before each decision.

Please note that each of the decisions you make in this part is independent and does not influence the future course of the study. For each decision you will be informed about the outcome, and the earnings you received, at the end of the study.

Please press the "Continue" button now to see the instructions for the first decision.

\section{Investment Decision}

The first decision is an investment decision. This decision is for real money; the result of your decision will be added to your account and paid to you at the end of the experiment.

You start the investment task with a balance of 100 ECU. You choose how much of this amount (from 0 ECU to $100 \mathrm{ECU})$ you wish to allocate to the investment.

The ECU that you choose not to invest will be saved in your account and cannot be lost. You will receive these ECU at the end of the experiment.

The value of the ECU you choose to invest depends on the success or failure of the investment.

The success or failure of the investment will be determined by a computerized random draw, similar to a coin flip. There are two possible outcomes:

- With $50 \%$ probability the investment fails and you lose the amount invested.

- With $50 \%$ probability the investment succeeds and you receive 2.5 times the amount invested.

So, for any amount $\mathrm{X}$ that you invest, you will keep $100-\mathrm{X}$, regardless of what happens with the investment. If the investment fails, which happens with $50 \%$ probability, your earnings from this decision will be $\mathbf{1 0 0}-\mathbf{X}$, since you lose the amount that you invested. If the investment succeeds, which also happens with $50 \%$ probability, your earnings from the decision will be $100-\mathrm{X}+2.5 * \mathrm{X}=\mathbf{1 0 0}+\mathbf{1 . 5} * \mathrm{X}$

Please enter the amount you wish to invest on your screen now. If you have any questions about the investment task please raise your hand and an experimenter will come to you.

Your Decision:

Please enter the amount of money (from ECU 0 to ECU 100) you wish to invest: $\mathrm{ECU}$

Once you enter a number, please submit your investment by clicking "Continue".

If you have any questions about the investment task please raise your hand and an experimenter will come to you.

\section{Allocation Decisions}

In the second task, you will make 15 decisions in which you allocate ECU between yourself and an anonymous other participant. You are again making decisions for real money; the payoff from this task will be added to your account and paid to you at the end of the experiment. Any money you allocate to another participant will be paid to another randomly selected participant at the end of the experiment.

For each of the 15 decisions, you will see a range of possible allocations. Your task in each decision is to choose your preferred allocation among the alternatives. 
After you have made your allocation decisions, one randomly chosen decision (among the 15) will be chosen for each participant and implemented. This means that you will receive payment for two randomly chosen decisions. This is because each decision involves a decision-maker and a receiver. You will be paid once for a randomly selected decision in which you chose, and once as a receiver for the allocation chosen by another participant. The participant you interact with in these two cases will not be the same. That is, the receiver from your implemented decision will not be the decision-maker in the decision for which you are the receiver.

Below you see a sample of what your screen will look like for each of the 15 allocation decisions. The numbers in this example are used only to illustrate the task and do not correspond to the numbers in the actual decisions. In the upper row, you will see the allocation for you, and in the bottom row the allocation for the randomly chosen receiver. In the example below, if you choose the leftmost allocation, you receive 1 and the other participant receives 9. If you choose the rightmost allocation, you receive 9 and the other participant receives 1. Notice that each time you select an allocation the corresponding payments for you and the receiver will be displayed to the right of the table.

\begin{tabular}{|c|c|c|c|c|c|c|c|c|c|c|c|}
\hline You receive & 1 & 2 & 3 & 4 & 5 & 6 & 7 & 8 & 9 & \multirow{3}{*}{$\begin{array}{r}\text { You receive } \\
\text { Other receives }\end{array}$} & 0 \\
\hline & $c$ & $c$ & $C$ & $\mathrm{C}$ & $c$ & $\mathrm{c}$ & C & C & C & & 0 \\
\hline Other receives & 9 & 8 & 7 & 6 & 5 & 4 & 3 & 2 & 1 & & \\
\hline
\end{tabular}

You will see 15 decisions, with varying allocations for you and another randomly selected participant. In each case, click on the button corresponding to the decision you would like to implement.

Once you are ready, please start the task by clicking "Continue".

If you have any questions about the allocation task please raise your hand and an experimenter will come to you.

\section{Questionnaire}

Before Part 1 ends, we would like you to answer a few additional questions. Please fill in your answers to the questions on the screen. If you have any questions raise your hand and an experimenter will come to you.

You confirm your entries by clicking the "Continue" button. Once everybody has answered these questions, Part 2 will begin.

1. First, state, in general, how willing or unwilling you are to take risks on a scale from 0 to 10.0 means you are "completely unwilling to take risks" and a 10 means you are "very willing to take risks". You can also use any integer number between 0 and 10 to indicate where you fall on the scale. Possible choices are: $0,1,2,3,4,5,6,7,8,9,10$.

2. Second, imagine the following situation: Today you unexpectedly received CHF 1,000. How much of this amount would you donate to a good cause? Values between 0 and 1,000 are allowed for the donation.

3. How old are you?

4. Are you male of female? 


\section{Instructions to Part 2}

In Part 2 you will work on a task for 90 seconds. You will be paid, as explained in more detail below, based on your performance on the task. You will also make a few decisions in which you can make additional money. Your actions in Part 2 are independent of the other parts of the study, and do not in any way influence the future course of the study.

\section{The Production Task}

The task for Part 2 consists of a coding task. During the task, your screen will display a key, which consists of a series of unique matches between letters and numbers. More precisely, each key will show the numbers 1-9, and a series of 9 letters of the alphabet, displayed such that one letter corresponds to one number. An example of such a key is in the picture below. In this example, $\mathrm{M}$ corresponds to $1, \mathrm{U}$ to $2, \mathrm{O}$ to 3 , and so on.

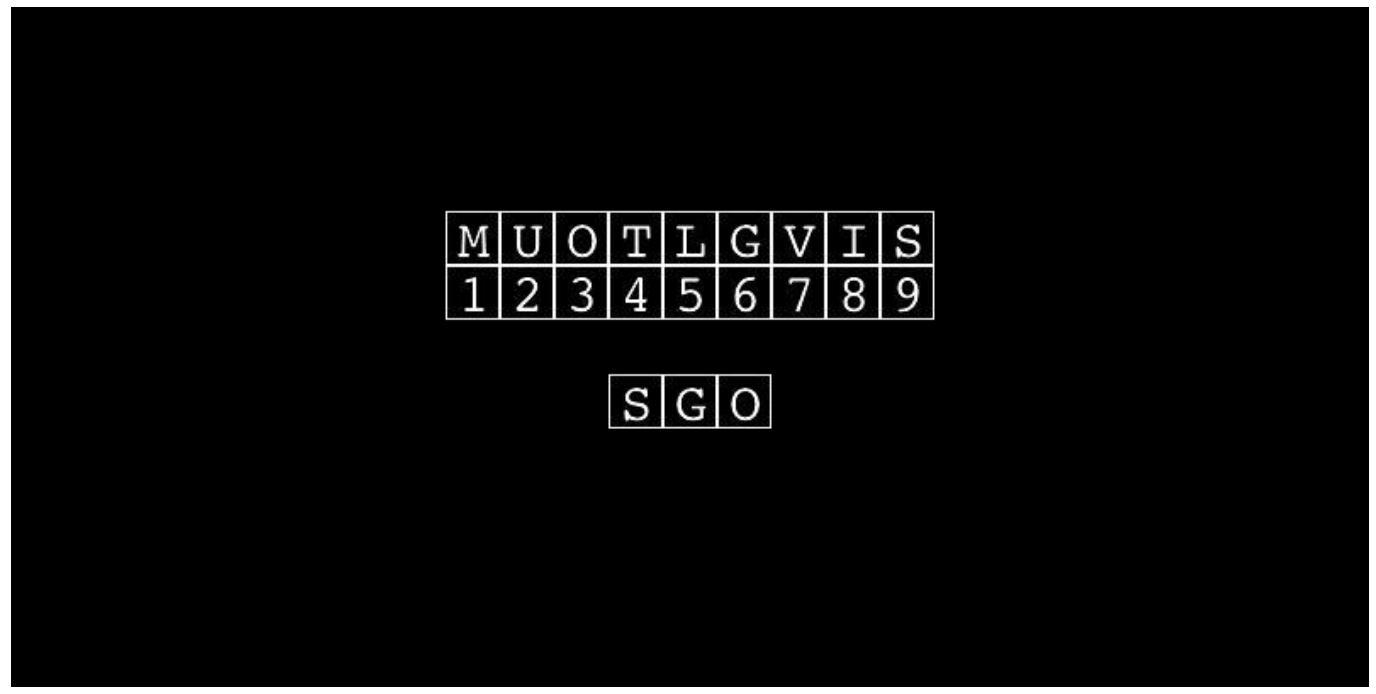

During the task, you will be shown sequences of three letters. Your task is to enter the corresponding three numbers on your computer. For example: if the sequence you are asked to code is SGO, as indicated in the picture, the correct answer for the key above is 963 . You obtain this sequence of numbers by exchanging the $S$ for a 9 , the $\mathrm{G}$ for a 6 , and the $\mathrm{O}$ for a 3 .

The sequences of three letters will appear on your screen, one at a time. Once you enter the corresponding three digits, you confirm your answer with the "OK" button. If the entered sequence is correct, a new sequence will appear on your screen, otherwise you will be asked to recode the three-digit sequence until it is entered correctly. For each key of letters and digits, you will see nine three-digit sequences to code into numbers. Then a new key appears, for which you will get nine consecutive three-digit codes, and so on. You will have 90 seconds to enter as many sequences as you can.

Your payment from the task depends on the number of sequences you code correctly. In particular, you will be paid 10 ECU per correctly coded sequence. At the end of the experiment, you will be informed about your resulting earnings.

On the next screen, you will see an example screen similar to the one you will see during the actual task. In the upper half of the screen you will see a picture of the key, consisting of nine letter-number pairs. Below that you will see the sequence of three letters that you are to recode into a three-digit number, as well as the box where you enter your answer. Remember that you will receive $10 \mathrm{ECU}$ for each sequence that you correctly type in during the 90 seconds.

Please click the "Continue" button on your screen now. You may then try the task on the example screen by filling in the correct three-digit number in the empty box. If the cursor is not positioned within the box, you will need to click inside the box to allow you to type in the box. Confirm your entry with the "OK" button. You will then be able to click to start the actual task for Part 2 . 
If you have any questions about the task please raise your hand and an experimenter will come to you.

\section{Part 2 - Additional Decisions}

To conclude Part 2, we would like to ask you a few questions related to the task you just completed.

First, we offer you the possibility to get paid once more for your performance in the task you just completed. This payment will be paid to you at the end of the experiment, in addition to all other payments, including the one you already earned for performing the task.

Specifically, we here ask you to make a choice regarding how you would like to be paid. In particular, you can choose between two different payment methods, method 1 and method 2.

\section{Payment method 1}

The first method is a certain payment of $10 \mathrm{ECU}$ per correctly entered three-digit sequence. This method is the same as the payment you already received for performing the task. If you choose this payment method, you will receive an additional payment of the same size as before. So, under payment method 1, your payment depends only on how many sequences you entered correctly.

\section{Payment method 2}

If you choose the second method, your performance will be compared to the performance of a randomly chosen participant present here today, which could be any other participant in the room. You will be paid 20 ECU per correctly entered sequence, only if you entered more three-digit sequences than this randomly chosen participant. If you entered fewer sequences than this randomly chosen person you get nothing. If you entered equally many sequences, then the computer will randomly decide, with equal probability, whether you receive 20 ECU per correctly entered sequence, or whether you receive 0 ECU. So, under payment method 2, your payment depends partly on whether you entered more or fewer sequences correctly than another randomly selected participant.

Please indicate your choice by clicking on the payment method according to which you would like to get paid. You confirm your choice by clicking "Continue."

If you have any questions about the task please raise your hand and an experimenter will come to you.

\section{Part 2 - Additional Decisions}

Finally, we ask you to assess your performance (how many three-digit sequences you coded correctly) during the 90 -second task, in comparison to the performance of the other participants in the room. Please enter your guess of your performance ranking in the box below. There are [Number of participants] participants present today. If you, for example, think that you copied the most sequences, and that no other participant copied as many, you enter the rank of 1 . If you think that 6 participants performed better than you, you enter the rank 7 . If you think you copied the fewest sequences, and that all other participants copied more than you, you enter the rank [Number of participants]. You submit your guessed rank by clicking the "Continue" button.

Please consider your guess well. You will earn an additional $50 \mathrm{ECU}$ if your answer lies within 2 ranks of the true one. That is, if your true ranking is only 0,1 , or 2 away from the rank that you guess, you will receive an extra payment of $50 \mathrm{ECU}$ at the end of the study.

If you have any questions about the task please raise your hand and an experimenter will come to you. Otherwise, please enter your guess below.

My estimated rank: 


\section{Instructions to Part 3}

Part 3 mainly comprises 10 periods of the decision-task described below. After the 10 periods, you will perform the same 90-second task as in Part 2 once more. We will then conclude the study with a short questionnaire.

At the beginning of Part 3, you will be randomly assigned to a group of 5 participants. For the remainder of the experiment, you will interact only with the other 4 participants in your group.

Each participant in a group will be randomly assigned a unique ID (A, B, C, D, or E). A participant's ID remains constant for the entire study and allows you to follow other group members across different periods. Participants will be identified only by ID number, meaning that you will not know the identity of any other participant with whom you interact and no other participants will know your identity.

The course of each of the 10 periods in Part 3 is the same. Each period contains 3 steps. Below, we give you an overview of these steps. We then explain each step in detail.

1. The vote: In each period the participants may generate money. As a first step in a period the five group members will vote how they intend to allocate the money the group members generate in that period. The result of the vote is presented to all group members directly after the vote.

2. The production task: As a second step, participants take part in the production task, in which each participant can generate ECU. This is the same as the task from Part 2.

3. Display of final earnings: After everyone has performed the task, the computer reallocates the money produced from the task among the group members, based on the outcome of the vote at the beginning of that period.

Below we will explain each step of a period in detail.

\section{The production task [No Risk Condition]}

In each period of Part 3, each group member may work on the same production task as in Part 2, coding sequences of three letters into digits for 90 seconds and generating 10 ECU per correctly coded sequence. However, a group member's final earnings in a period may differ from the money that person generates in the production task. How the final earnings differ from the money generated in the production task depends on the outcome of the group vote.

\section{The production task [Risk Condition]}

In each period of Part 3, each group member may work on the same production task as in Part 2, coding sequences of three letters into digits for 90 seconds and generating ECU.

Unlike in Part 2, the productivity values will now vary randomly between group members and periods. Specifically, in each period, the computer will randomly draw a new productivity value, with equal probability, from all integer values between 0 and 20, for each group member. This means that your productivity value in a period is equally likely to be any value from $0,1,2, \ldots, 19$ or 20 . The ECU that you generate from the production task in a period will be the number of sequences you correctly code, multiplied by the randomlydetermined productivity value.

Since your productivity value in a period is randomly drawn, it does not depend on the productivity value of any other participant, any previous productivity values, or any previous performance or decisions made in the experiment. Each member of a group may have a different productivity value. You will not know the value of your productivity value, or the values for anyone in your group, until the end of the period.

In Part 3, the ECU generated from the production task in a period differs between group members based on two things; the number of sequences that member codes correctly and that group member's randomly determined productivity value. 
A group member's final earnings in a period may differ from the money that person generates in the production task. How the final earnings differ from the money generated in the production task depends on the outcome of the group vote.

\section{The vote}

At the beginning of each period, before participating in the production task, the members of a group will vote on a rule for reallocating the money generated by each of the five group members in the production task. This vote is taken before knowing the exact amounts of money generated by each group member in the task.

Specifically, group members must vote on a transfer parameter, $\mathbf{t}$. Via their vote on $\mathbf{t}$, the group members have the possibility to influence the final distribution of earnings among the group members in a period.

The final earnings in a period are determined by collecting a share of the earnings produced by each group member and by then redistributing this collected amount among the group members. The amount collected from a member may differ from the transfer the member gets back.

The transfer parameter, $t$, indicates how large the effect is on the individual earnings. Specifically, $t$ has two effects:

1. First, the distance of $\mathbf{t}$ from zero indicates how much redistribution takes place. When $\mathbf{t}=\mathbf{0}$, then all group members keep the money they generated in the production task and no redistribution takes place. As t gets farther from zero, a larger share of the group's total production is collected for redistribution. The values of $\mathrm{t}$ can range from -1.00 to 1.00 .

2. Second, $t$ can be either positive, meaning it is greater than zero, or negative, meaning it is lower than zero. When $\mathbf{t}$ is positive, this means that the redistribution primarily collects money from those who generated more money in the production task and rewards those who generated less money in the production task. When $\mathbf{t}$ is negative, this means that the redistribution primarily rewards those who generated more money in the task and collects money from those who produced less in the production task.

We will explain in detail below what different values of $t$ imply for the final payoffs, and illustrate it with a few examples.

At the beginning of a period, all group members vote for $\mathrm{t}$ by stating their preferred value. Each group member can propose any value of $t$, with a precision of two decimals, between -1.00 and 1.00.

Once the votes are cast, the group members' 5 proposed values for $t$ are compared, and the median value is implemented for the group in the relevant period. The median is the value that lies in the middle when the five votes are ordered from highest to lowest. In each period, a new vote is taken and $\mathbf{t}$ takes the value of the median vote for that period. Thus, depending on the votes by the group members, $t$ may take a new value in each period.

Note that using the median vote means that each participant does best by specifying the true value of $\mathrm{t}$ that they prefer. That is, there is no reason to try to strategically manipulate your vote. Your vote cannot affect the value of $\mathrm{t}$, unless it lies in the middle of all the votes and in that case your vote determines $\mathrm{t}$ for that period.

\section{Final earnings: The transfer parameter $t$}

The transfer parameter allows the group members to influence the final earnings in a period. Depending on the value of $t$, groups may choose to either compensate group members who generate less money in the production task (who coded fewer sequences) or to reward group members who generate more money. In particular,

- $\quad$ if the value of $t$ is positive, group members who generated less money than the group average end up benefitting from the redistribution; 
- if the value of $t$ is negative, group members who produced more money than the group average end up benefitting from the redistribution.

We will now provide you with the formula that determines how $t$ affects the earnings of group members. However, if you do not understand the formula in detail, do not worry. The key facts to remember are that i) the farther $t$ is from zero the more redistribution takes place and ii) a positive value of $t$ benefits those who generated less money than the group average while a negative value of $t$ benefits those who generated more money than the group average.

Let $x_{i}$ denote the money generated by participant $\mathrm{i}$ in the production task, and $\mathrm{t}$ the transfer parameter. Remember that there are 5 participants in each group. You can calculate the individual final earnings in a period according to the formula below (we also illustrate the formula with two examples).

$$
\operatorname{Payoff}\left(x_{i}\right)=\left(\begin{array}{ll}
1 & t
\end{array}\right) x_{i}+t * \frac{1}{5}_{i}^{5} x_{i}
$$

\section{The case when $0<t \leq 1$}

If $t$ is positive, a fraction equal to $t$ is collected from the money generated by each member in the production task. This means that the group member keeps $(1-t)$ of the money that group member generated in the production task. That is, when $t$ is positive, each group member keeps the sum $(1-t) * x_{i}$, while contributing $t * x_{i}$ to the common pool. This is illustrated in the first term of the payoff equation.

For example, if $\mathrm{t}=0.5$, half of the money generated (50\%) from production is collected from each group member. Each group member keeps the remaining half. Thus, participants who generated more money pay higher amounts to the common pool than participants who generated lower amounts.

The money collected from all five group members is added up, divided into 5 equal parts, and returned to the group members, such that the total sum collected from the 5 group members always equals the sum paid out. This is illustrated in the second term of the payoff equation, $\mathrm{t}^{*} 1 / 5 \sum \mathrm{x}_{\mathrm{i}}$.

Thus, all participants in a group pay different amounts in, which are proportional to their earnings from the task, but get the same amount back. Therefore, if $t$ is positive, group members who generated less money than the average receive more money back than they contribute, whereas those who generated more money than the group average receive less money back than they contribute.

\section{Example:}

We will now go through an example. Please note that the numbers used in this example are also shown on the table on the next page.

- Assume that the five votes for the transfer parameter are: $-0.5,-0.3,0.4,0.5$ and 0.7 .

- The median vote is thus 0.4 , and implies that each group member will contribute a share of 0.4 ( 40 percent) of the money they generated to the common pool.

- Assume further that the ECU generated from production by the five group members are 50, 100, 150, 200 and 250 .

- In this case, a value of $\mathrm{t}=0.4$ means that participant $\mathrm{A}$, who generated $50 \mathrm{ECU}$ in the production task, contributes $20 \mathrm{ECU}(0.4 * 50=20)$ to the common pool, and keeps $30 \mathrm{ECU}(50 *(1-0.40)=30)$. The other group members contribute $40,60,80$ and $100 \mathrm{ECU}$, respectively.

- The common pool is then, in total, $300 \mathrm{ECU}(20+40+60+80+100=300)$.

- The common pool is divided in 5 equal shares of 60 ECU. Each of the five group members receives an equal share. 
- Thus, the final earnings for the period for participant A are 50 - 20 +60 $=90 \mathrm{ECU}$, for participant B the final earnings are $100-40+60=120 \mathrm{ECU}$, and so on.

The table below shows you, for each group member, the ECU generated in the production task, the amount collected from that group member and placed into the common pool, the amount paid back to that group member, and the final earnings of the group member in the example above.

Since $t$ is greater than zero, group members who generate more money in the production task contribute more to the common pool, and members who generate less money in the production task contribute less, while all members get an equal share back from the common pool.

As you can see, when $\mathrm{t}$ is positive, it decreases the payment differences arising in the task.

\begin{tabular}{|c|c|c|c|c|c|}
\hline & $\mathbf{A}$ & B & $\mathbf{C}$ & D & $\mathbf{E}$ \\
\hline Vote for $t$ & -0.5 & -0.3 & 0.4 & 0.5 & 0.7 \\
\hline $\begin{array}{l}\text { Value of } t \text { for group } \\
\text { (median vote) }\end{array}$ & & & 0.4 & & \\
\hline $\begin{array}{l}\text { ECU generated by } \\
\text { production (xi) }\end{array}$ & 50 & 100 & 150 & 200 & 250 \\
\hline $\begin{array}{l}\text { Amount collected } \\
\left.\text { (Proportional: } \mathbf{t}^{*} \mathbf{x i}\right)\end{array}$ & $\begin{array}{c}\mathbf{2 0} \\
0.4 * 50=20\end{array}$ & $\begin{array}{c}\mathbf{4 0} \\
0.4 * 100=40\end{array}$ & $\begin{array}{c}\mathbf{6 0} \\
0.4 * 150=60\end{array}$ & $\begin{array}{c}\mathbf{8 0} \\
0.4 * 200=80\end{array}$ & $\begin{array}{c}100 \\
0.4 * 250=100\end{array}$ \\
\hline Total amount collected & \multicolumn{5}{|c|}{300} \\
\hline $\begin{array}{l}\text { Amount paid back } \\
\text { (Equal: total amount } \\
\text { collected/5) }\end{array}$ & $\begin{array}{c}\mathbf{6 0} \\
300 / 5=60\end{array}$ & $\begin{array}{c}\mathbf{6 0} \\
300 / 5=60\end{array}$ & $\begin{array}{c}\mathbf{6 0} \\
300 / 5=60\end{array}$ & $\begin{array}{c}\mathbf{6 0} \\
300 / 5=60\end{array}$ & $\begin{array}{c}\mathbf{6 0} \\
300 / 5=60\end{array}$ \\
\hline Total amount paid back & \multicolumn{5}{|c|}{300} \\
\hline Net gain/loss & $\begin{array}{c}\mathbf{4 0} \\
60-20=40\end{array}$ & $\begin{array}{c}\mathbf{2 0} \\
60-40=12\end{array}$ & $\begin{array}{c}\mathbf{0} \\
60-60=0\end{array}$ & $\begin{array}{c}-\mathbf{2 0} \\
60-80=-20\end{array}$ & $\begin{array}{c}-40 \\
60-100=-40\end{array}$ \\
\hline Final earnings & $\begin{array}{c}90 \\
50+40=90\end{array}$ & $\begin{array}{c}120 \\
100+20=120\end{array}$ & $\begin{array}{c}150 \\
150+0=150\end{array}$ & $\begin{array}{c}180 \\
200-20=180\end{array}$ & $\begin{array}{c}\mathbf{2 1 0} \\
250-40=210\end{array}$ \\
\hline
\end{tabular}




\section{The case when $-1 \leq t<0$}

If $t$ is negative then $1-t$ is larger than 1 , which means that the first term of the payoff equation, $(1-t) * x_{i}$ is larger than $\mathrm{x}_{\mathrm{i}}$. This means that the group members receive an additional payment equal in a to $\mathrm{t}^{*} \mathrm{x}_{\mathrm{i}}$. Thus, contrary to the case where $t$ is positive, when $t$ is negative the sum paid out to the group members is proportional to the sum of money they generated in the production task. Group members who produced more money receive a larger payment, and group members who produced less receive a smaller payment.

For example, if $\mathrm{t}=-0.5$, each of the group members get an additional payment corresponding to 50 percent of the money that group member generated in the production task, or $0.5^{*} \mathrm{x}_{\mathrm{i}}$. Thus, participants who generated more money receive higher amounts.

The total money that is to be paid out to the group members is collected in equal shares from all the group members. Specifically, the 5 amounts to be paid out are added up and divided into 5 equal parts. Each group member pays one of these equal shares. This is illustrated in the second term of the payoff equation, $\mathrm{t}^{*} 1 / 5 \sum \mathrm{x}_{\mathrm{i}}$. The amount is equal to the average of the payments made to the five group members.

Thus, all participants in a group get different amounts back, which are proportional to their earnings from the task, but pay the same amount in. Therefore, if $\mathrm{t}$ is negative, group members who generated less money than the average receive less money back than they contribute, whereas those who generated more money than the group average receive more money back than they contribute.

\section{Example:}

We will now go through an example. Please note that the numbers used in this example are also shown on the table on the next page. [Addition Risk Condition: In this example, and all subsequent examples, we will assume that the productivity values for everyone in the group are equal to 10 . This is to keep the examples simple and keep all numbers as multiples of 10 . Note, however, that this will likely not be the case, since productivity values will be randomly determined for all group members in every period, and can vary from 0 to 20.]

- Assume that the five votes for the transfer parameter are: $-0.7,-0.5,-0.4,0.3$ and 0.5 .

- The median vote is thus -0.4 , and implies that each group member will receive an additional payment equal to 0.4 ( 40 percent) of the money they generated.

- Assume further that the ECU generated from production by the five group members are, as before, 50, 100, $150,200,250$.

- In this case, a value of $\mathrm{t}=-0.4$ means that participant $\mathrm{A}$, who generated $50 \mathrm{ECU}$ in the production task, receives 20 ECU $(0.4 * 50=20)$. The other group members receive 40, 60, 80 and 100 ECU, respectively.

- The total sum of payments to the group members is then $300 \mathrm{ECU}(20+40+60+80+100=300)$.

- The total sum of payments is collected from the group members as 5 equal shares of $60 \mathrm{ECU}$ each $(300 / 5=$ $60)$.

- Thus, the final earnings for the period for participant A are 50+20-60=10 ECU, for participant B the final earnings are $100+40-60=80 \mathrm{ECU}$, and so on.

The table below shows you, for each group member, the ECU generated in the production task, the additional payment to that group member, the amount collected from that group member, and the final earnings of the group member in the example above.

Since $t$ is less than zero, group members who generate more money in the production task receive a larger additional payment, and members who generate less money in the production task receive less, while all members contribute an equal share to the common pool. 
As you can see, when $t$ is negative, it rewards those group members who generate more money in the production $\underline{\text { task. }}$

\begin{tabular}{|c|c|c|c|c|c|}
\hline & $\mathbf{A}$ & B & $\mathbf{C}$ & D & $\mathbf{E}$ \\
\hline Vote $(t)$ & -0.7 & -0.5 & -0.4 & 0.3 & 0.5 \\
\hline $\begin{array}{l}\text { Value of } t \text { for group } \\
\text { (median vote) }\end{array}$ & \multicolumn{5}{|c|}{-0.4} \\
\hline $\begin{array}{l}\text { ECU generated by } \\
\text { production (xi) }\end{array}$ & 50 & 100 & 150 & 200 & 250 \\
\hline $\begin{array}{l}\text { Additional payment } \\
\text { received (Proportional: } \\
t^{*} \mathbf{x i} \text { ) }\end{array}$ & $\begin{array}{c}20 \\
0.4 * 50=20\end{array}$ & $\begin{array}{c}\mathbf{4 0} \\
0.4 * 100=40\end{array}$ & $\begin{array}{c}\mathbf{6 0} \\
0.4 * 150=60\end{array}$ & $\begin{array}{c}\mathbf{8 0} \\
0.4 * 200=80\end{array}$ & $\begin{array}{c}100 \\
0.4 * 250=100\end{array}$ \\
\hline Total amount paid back & \multicolumn{5}{|c|}{300} \\
\hline $\begin{array}{l}\text { Amount collected } \\
\text { (Equal: total amount } \\
\text { paid back/5) }\end{array}$ & $\begin{array}{c}\mathbf{6 0} \\
300 / 5=60\end{array}$ & $\begin{array}{c}\mathbf{6 0} \\
300 / 5=60\end{array}$ & $\begin{array}{c}\mathbf{6 0} \\
300 / 5=60\end{array}$ & $\begin{array}{c}\mathbf{6 0} \\
300 / 5=60\end{array}$ & $\begin{array}{c}\mathbf{6 0} \\
300 / 5=60\end{array}$ \\
\hline Total amount collected & \multicolumn{5}{|c|}{300} \\
\hline Net gain/loss & $\begin{array}{c}-40 \\
20-60=-40\end{array}$ & $\begin{array}{c}-\mathbf{2 0} \\
40-60=-20\end{array}$ & $\begin{array}{c}\mathbf{0} \\
60-60=0\end{array}$ & $\begin{array}{c}20 \\
80-60=20\end{array}$ & $\begin{array}{c}\mathbf{4 0} \\
100-60=40\end{array}$ \\
\hline Final earnings & $\begin{array}{c}10 \\
50-40=10\end{array}$ & $\begin{array}{c}\mathbf{8 0} \\
100-20=80\end{array}$ & $\begin{array}{c}150 \\
150+0=150\end{array}$ & $\begin{array}{c}220 \\
200+20=220\end{array}$ & $\begin{array}{c}290 \\
250+40=290\end{array}$ \\
\hline
\end{tabular}




\section{Three special cases}

Below we further illustrate the effects of $t$ by three special cases:

- If $\mathrm{t}=1,100$ percent of the ECUs the group members generate through production is collected and transferred back in equal amounts. Thus, if $t=1$, all group members end up with the same final earnings in a period, regardless of how much money they generate from the production task.

In the example above, the group members generated 750 ECU from the production task in total. If $\mathrm{t}=1$, the entire 750 would be collected into the common pool and each group member would thus receive a final payoff of $750 / 5=150 \mathrm{ECU}$.

- If $\mathrm{t}=0$, nothing is collected from the money the group members generate from production. In this case, each group member receives, as final payoff, the amount that group member generated from production in the task.

- If $\mathrm{t}=-1$, the final earnings for the group members who generated the least money in the production task may end up being negative. However, earnings may not be negative for any participant or period. Therefore, we restrict $t$ such that the lowest earnings possible in a period will be 0 . If the median vote for $t$ ends up, at the end of the period, leaving any group member with negative final earnings in that period, then the computer adjusts $t$ upwards until no group member is left with negative earnings.

For example, assume that in the example above $t=-1$. This implies that each group member receives an additional payment equal to the amount that group member generated from production. The group member who generated $50 \mathrm{ECU}$ receives an additional payment of $50 \mathrm{ECU}$. This also means that a total of $750 \mathrm{ECU}$ is paid out and an equal sum of 750/5 = 150 ECU is collected from each group member. The final earnings of the group member who generated $50 \mathrm{ECU}$ would then be $50+50-150=-50 \mathrm{ECU}$. Hence with this distribution of money generated from production, a value of $t$ equal to -1 cannot be implemented, since earnings cannot be negative. Instead, the lowest value of $t$ that leaves no group member with negative earnings will be implemented. In this example, the lowest value of $t$ that satisfies this requirement is $t=-$ 0.5 , which leaves the least productive group member with final earnings of 0 ECU.

Before we continue, you will have the opportunity to familiarize yourself with how $t$ influences final payoffs. Please click "Continue" on your screen now. You will then see an example of a practice screen in which you can test the effect of different values of t on the distributions of final earnings.

You now see an example of the practice screen. At present, you cannot insert any values. Once I describe the screen, you will again be asked to click "Continue" and the real practice screen will appear.

The practice screen allows you to enter various values of $\mathrm{t}$, and see how these values influence the redistribution and final earnings, for different amounts of money generated by the members of a group.

In the upper part of the screen, under "Transfer parameter" you can fill in hypothetical values for the transfer parameter, t. During the experiment, the transfer parameter will be decided by the median vote cast by the group's members.

In the table below, under "Redistribution" you can fill in hypothetical amounts of money generated in the production task for each of the five group members.

Once you have filled in hypothetical values, you can click "OK", and the table then displays, for each group member, the amount collected from that group member, the amount of money received by that group member, the corresponding net transfer, and the final earnings for that group member.

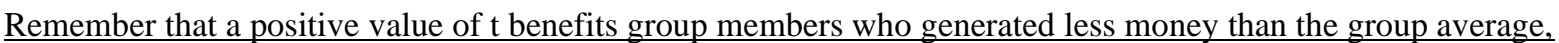
and a negative value of $t$ rewards group members who generated more money in the task than the group average.

Please now press "Continue" to get to the practice screen. You will then have 3 minutes to test different combinations of $\mathrm{t}$ and the money generated by group members. If you need a calculator, you can click on the symbol in the lower right corner, and a calculator will become visible. 


\section{Information about current and previous periods}

In each period, after all group members vote on the value of $t$ in a period, you will see the transfer parameter, $t$, for your group for that period. You will see this before starting the production task for that period.

In addition, at the end of each period you will see a feedback screen with information about the outcome of the current period for all members of your group. [Addition Risk Condition: At this point, you will also be told of your productivity value for that period.]

[No Risk Condition] Specifically, you will see the value of the transfer parameter, as well as a table including the amount of money each group member generated from production, the group member's rank in the group for that period, and the net transfer and final earnings for each group member. For each group member, you will also see the average amount of money produced by that group member across all previous periods.

[Risk Condition] Specifically, you will see the value of the transfer parameter, as well as a table including the number of sequences each group member completed, each group member's productivity value for that period, the amount of money each group member generated from production, the group member's rank in the group for that period, and the net transfer and final earnings for each group member. For each group member, you will also see the average amount of money produced by that group member across all previous periods

The information screen will also provide the transfer parameter and all group members' production and final earnings for all periods. This will be at the bottom of the screen, in a scrollable box.

In addition, at the beginning of each period, before you vote for a value of $t$, a screen will be available for up to 60 seconds where you may calculate the effect on final earnings due to different values of t. On this screen, you can also find the results of previous periods, as well as individual average production and earnings across previous periods.

\section{Comprehension Questions}

Before starting the first period of Part 3, we would like you to answer a few questions to ensure everyone understands the instructions. Please click the "Continue" button on your screen now. You will then see a table with an example of the votes for a hypothetical group. A few cells in this table are empty.

First, we ask you to fill in the transfer parameter, given the hypothetical votes given by the group members. Please remember that the median is the value that lies in the middle when the five votes are ordered from highest to lowest.

Once you have confirmed the correct answer, the next part of the table, which displays the outcomes of the production task, appears. Please continue entering the correct amounts collected or paid back to the group members where this information is missing. In total, you will see two different examples.

If anything is unclear, please raise your hand and an experimenter will assist you. When everybody has answered the comprehension questions Part 3 will start. 